\title{
البيانات الضخمة في المكتبات: الماهية والأهمية
}

\section{د. أحمد سعد الدين بسيبوني}

$$
\begin{gathered}
\text { كبير أخصائيين - الكتب النادرة } \\
\text { ahmed.bassiouni@bibalex.org } \\
\text { مكتبة الإسكندرية }
\end{gathered}
$$

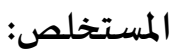

يعد تحليل البيانات الضـخمة من أهم مصــادر المعلومات التي ظهرت في الســـوات الأخيرة في مختلف المجالات الإنتـاجيـة والخـدمية ومنهـا المكتبـات، ورغم انتشـــارها وانتشـــار

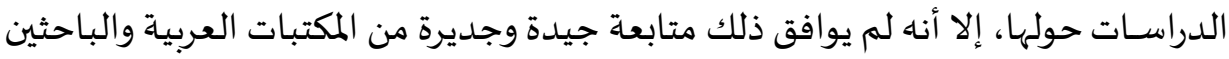

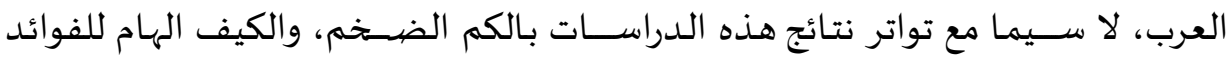

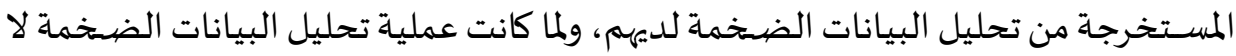

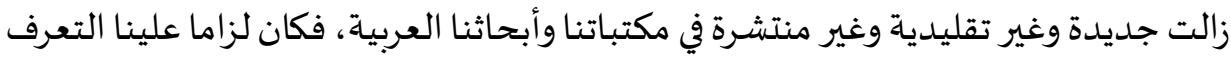

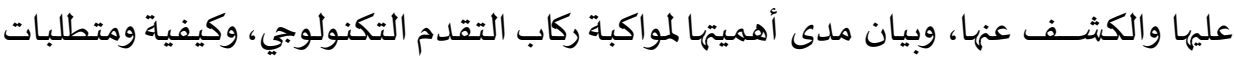

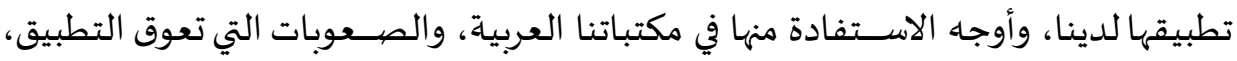

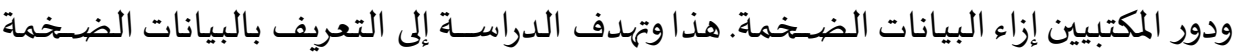

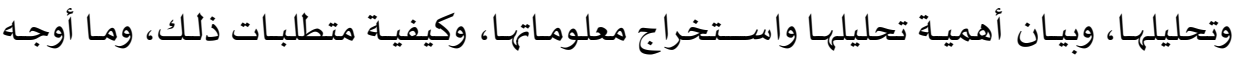
الاستفادة، صعوبات التطبيق، ودور المكتبيين.

ولإتمام هذه الدراســـة اســتخدم الباحث البحث الوثائقي المتمثل في مراجعة الإنتاج الفكري المنشـور، والبحث في الدراسات السابقة ذات الصلة مستخدماً المنههج الوصفي التحليلي لتحليل المحتوى. - الم الكلمــات المفتاحيــة: البيانـات الضــخمة، المكتبــات، تـأثيرات ثــورة البيانــات، تحسـديات ثورة البيانات. 
لم تعد البيانات الضخمة اليوم عاملا رئيسا في عالم الأعمال فحسب، بل تخطت هذا

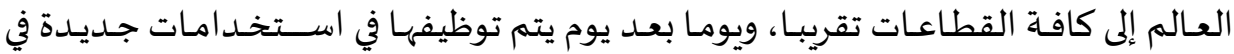

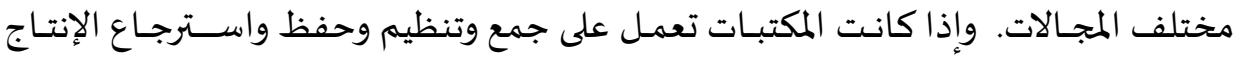

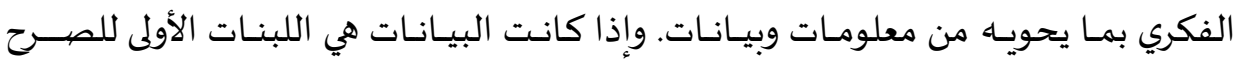

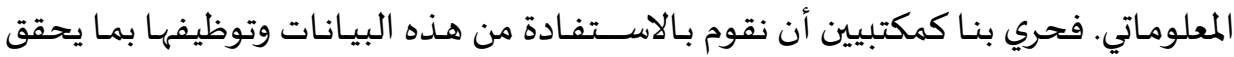

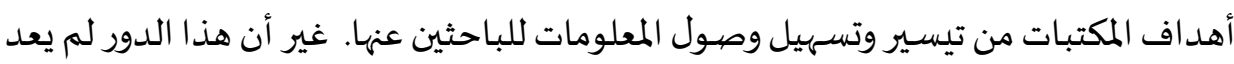

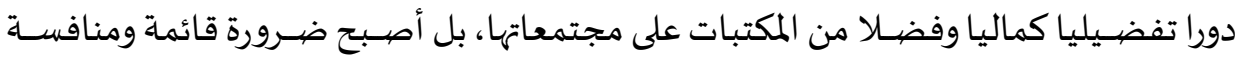

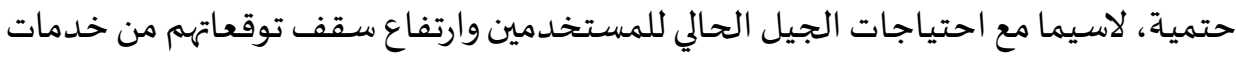

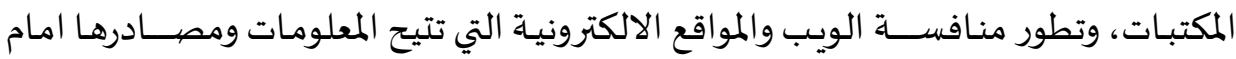

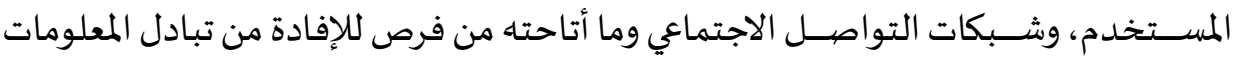

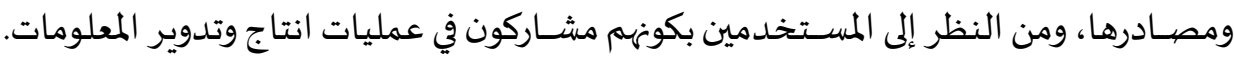

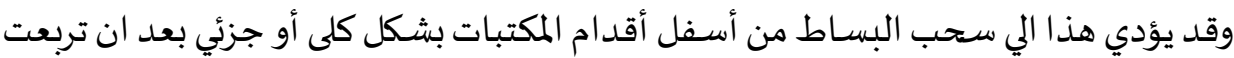

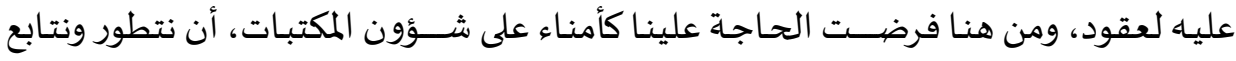

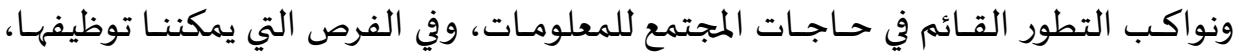
والتهديدات التي من شأهها تحويل قبلة الباحثين من المكتبة إلي حيث الويب وبيئتها.

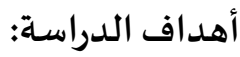

ولما كانت ماهيـة وأهمية البيانات الضــخمة غائبة عن كثير من القائمين على أمور

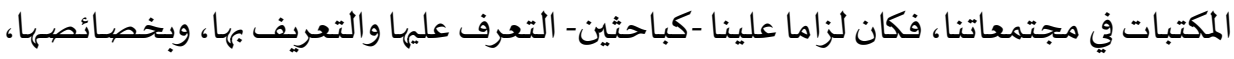

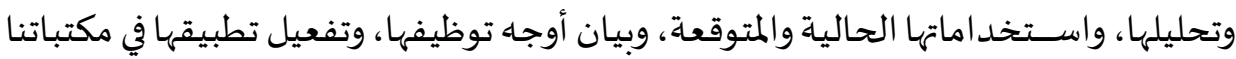

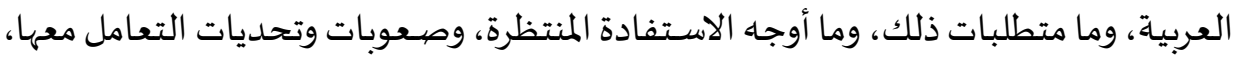
ودور المكتبيين المنشود لتحقيق ذلك.

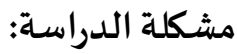

يتوافر لدى المكتبات العربية كم هائل من البيانات الضـخممة، المتنوعة الأشــكال،

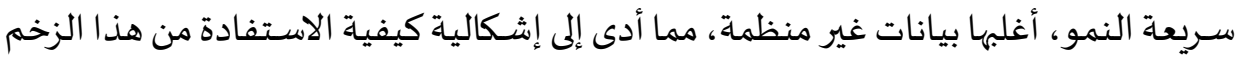


الهائل من البيـانـات الضــخمـة؛ من أجل تحســين وتطوير خـدمات المكتبـات، وتقليل الجهـد

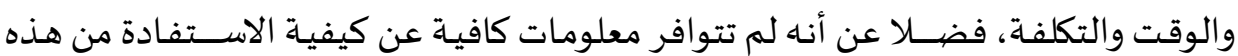
البيانات الضخمة في المكتبات، أو استخدامها وانها في التخطيط المستقبلي للمكتبات.

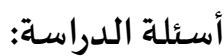

تسعى الدراسة إلى الاجابة على الأسئلة التالية:

- ما هو تعريف البيانات الضخمة ؟وما أهميتها؟ وخصيائصها؟ -

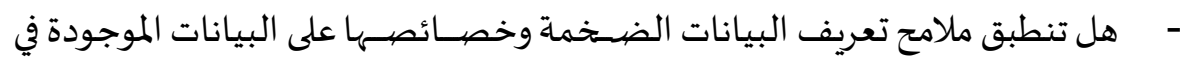

المكتبات؟ هل تلع

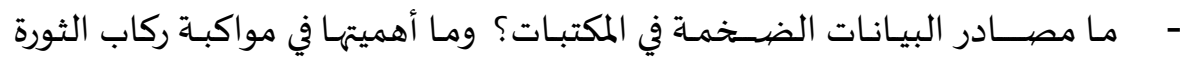

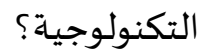

- وكيفية تفعيل وتطبيق عملية تحليل البيانات الضـخمة في المكتبات؟ وما متطلبات

$$
\text { تفعيل هذا التطبيق؟ وكيفي تفعيل وتطبيق }
$$

- ما أوجه الاستفادة العائدة من تحليل البيانات الضخمة في المكتبات؟ وما الصعوبات

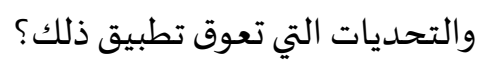

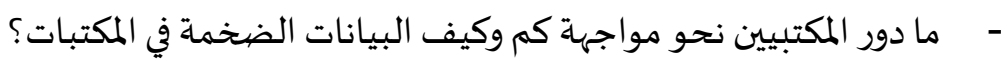

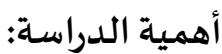

تكتسـب الدراســة أهميتها من أهمية الموضـــوع الذي يعد من الموضــوعات الحديثة

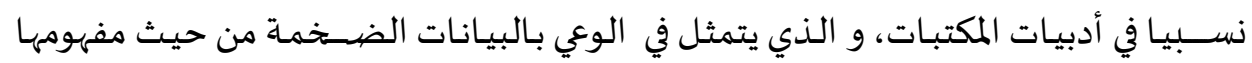

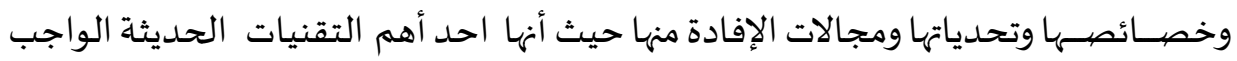

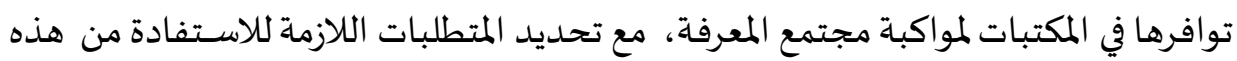

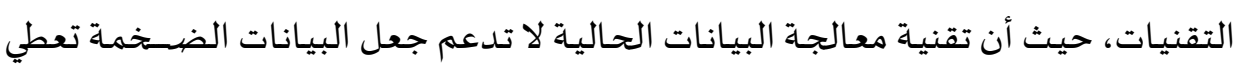

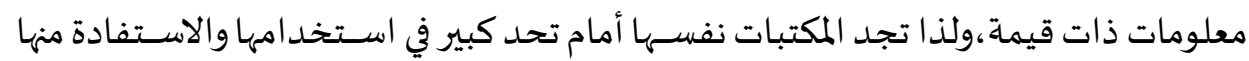

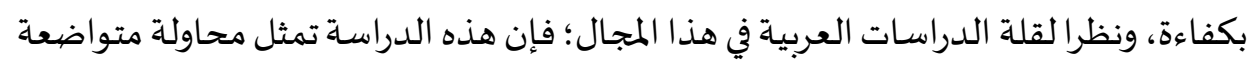
لسد النقص في هذا المجال ونظرال 
وفقا لطبيعة موضـوع الدراسـة، وأهدافها، وتســاؤلاتها التي تسـعى للإجـابة عليها، فقد اعتمدت الدراسـة على المنهج الوصـفي التحليلي، لذا فتعتبر الدراسـة دراسـة وصـفية تحليلية (وثـائقيـة) تمثلـت في مراجعـة الإنتـاج الفكري العربي المنشـــور بين 2017 وللآن، والبحـث في الدراسـات السـابقة ذات الصلة، وعليه فإن الباحث اعتمد المنهج الوصفي التحليلي. واستخدم للطريقة البحثية الرئيسـية طريقة تحليل المحتوى، واسـتخدم الملاحظة الوثائقية لأدوات جمع البيانات، وباعتبار أن الدراسـة تستخدم المنهج الوصيفي التحليلي وتعتمد في تحقيق هدفها على الإجـابـة على الهـدف الرئيسـي والأهـداف الفرعيـة. هـا وقام البـاحث بـالبحث عن الدراســات المتعلقة بالبيانات الضـــمـة، من خلال شــبكة الويب المفتوحـة، ثم من قواعد بيانات مكتبـة الاسـكندرية باسـتخدام أداة البحث الموحد Summon؛ وبنك المعرفة المصـري. وقد تم الاطلاع على أدبيات موضــوع الدراســة في المصــادر التقليدية و الالكترونية ومن خلال البحث في قواعد البيانات التاليـة: (LISTA) ومســتخلصــــات الرســائل الدوليـة (DAI) ومركز معلومات المصـادر التربوية (ERIC) وتم فحص الدراسـات المنشـورة 2017 وحتى تاريخ إجراء الدراسـة في ينـاير 2020 ، ولعل من أهم الدراســات التي أفـادت البـاحث، تلك الدراســات التي قدمت في المؤتمر السـنوي الرابع والعشـرون لجمعية المكتبات المتخصـصـة فرع الخليج العربي. مسـقط : جامعة السلطان قابوس) 6- 8 مارس(2018 تحت عنوان البيانات الضشخمة وآفاق اسـثمارها : الطريق نحو التكامل المعرفي، حيث قدمت فيـه العـديد من الأوراق البحثيـة البـارزة والتي اطلع عليها الباحث جميعـا، وكذلك اطلع الباحث على عددا من أوراق مؤتمر التنمية الإدارية في ظل التحديات الاقتصيادية) الذى نظمه معهد الإدارة العامة خلال الفتـــرة 22-24 نوفمبر 2016م. في مركز الملك سلمان للمؤتمرات بمدينة الرياض بالمملكة العربية السعودية، فضلا عن العديد من أوراق المؤتمر العلمي السـادس والعشـرون لنظم المعلومات وتكنولوجيا الحاسـبات - ثورة البيانات لتعزيز التخطيط القومي والتنمية المسـتدامة 2019 القاهرة- مصير ـ معهد التخطيط القومي، الجمعية المصيـريـة لنظم المعلومات وتكنولوجيا الحاسـبـات. مارس 2019، وتم البحث الكلمات الرئيسية المستخدمة هي:Big Data ، البيانات الكبيرة، تقنيات تحليل البيانات الكبيرة، أدوات البيانات الكبيرة، المكتبات. تم اسـتبعاد الأوراق التي لم ترتبط مباشـرةً بالنقاط البحثية. 
ثم قام الباحث بفحص وتصنيف وتحليل هذه الأعمال في مجالات المعرفة المختلفة وفقًا لأسئلة البحث.

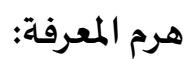

يتكون هرم المعرفة من أربع درجات حيث يبدأ من قاعدة الهرم بالبيانات التي تشــمل أحسل

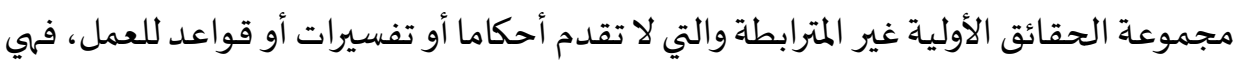

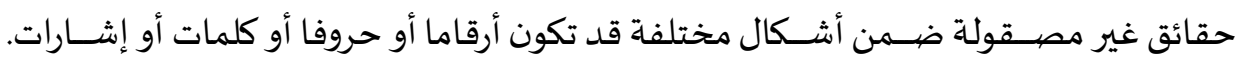

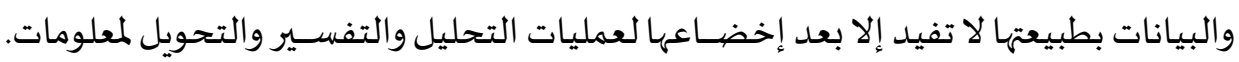

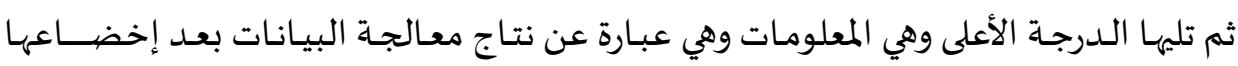

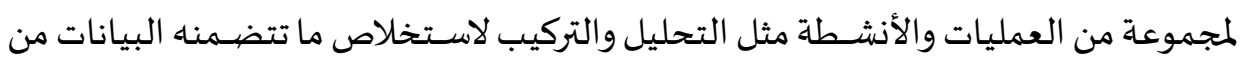

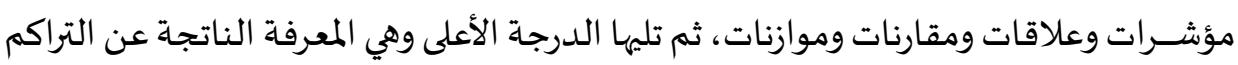

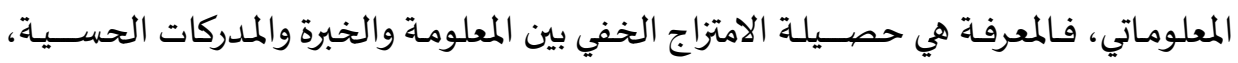

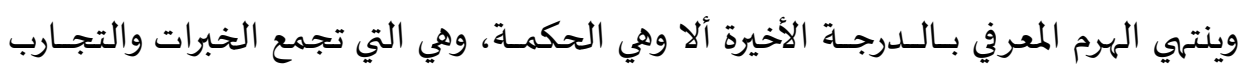

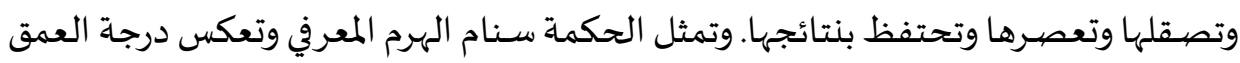

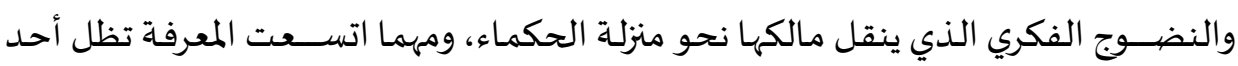

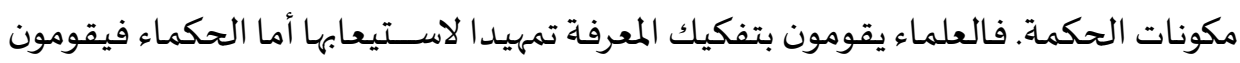
بتركيب المعرفة لبناء وتشكيل رؤية شـاملة تنصهر فيها كافة العلوم والمعارف المعلنة والضيمنية. غير أنها ليس كل تراكم معرفي يعد حكماة، فهذا الأمر يحتاج لتدقيق وانتقاء وتحليل

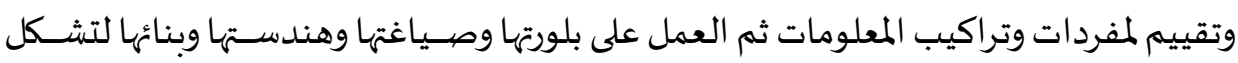

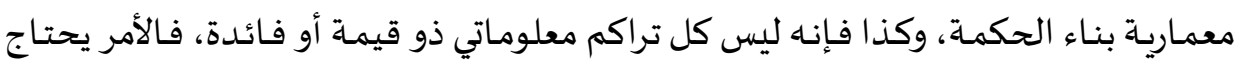

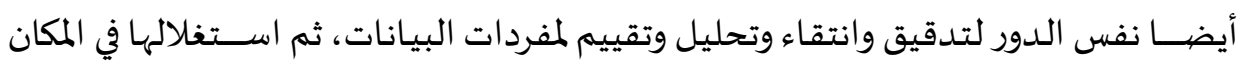

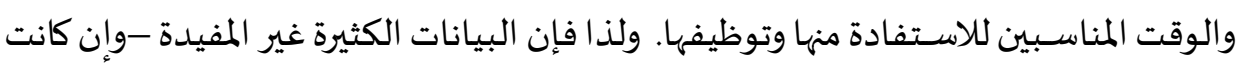

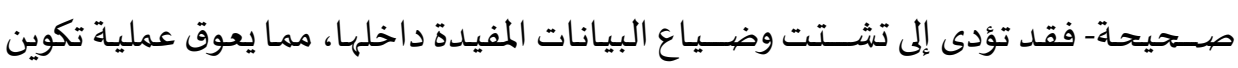

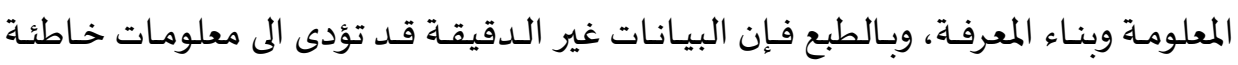

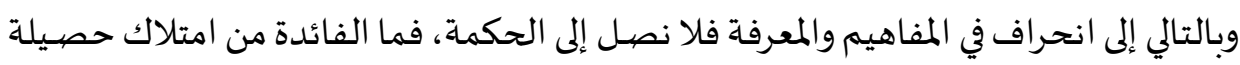
معلوماتية أو حتى معرفية ضسخمة لا تفيد ولا يمكن توظيفها في معرفة الواقع واتخاذ القرارات 
والتخطيط والاستشراف للمستقبل، وعليه فإن عمليات الانتقاء والتقييم للبيانات والمعلومات

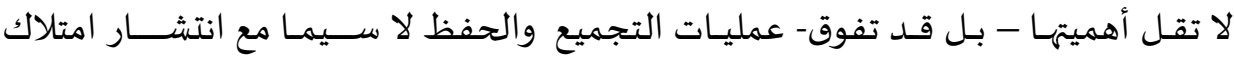
تكنولوجيات تطبيقات الحواسب والهواتف الذكية ووصيولها للمستخدمين، الأمر الذى جعلهم

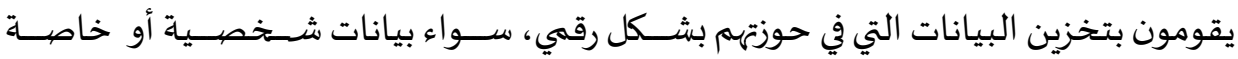

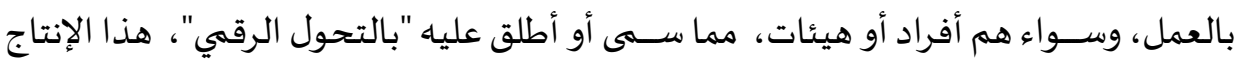

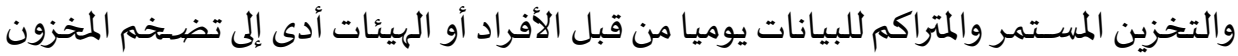

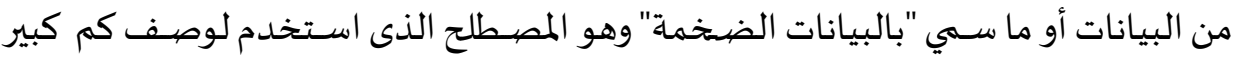
جدا وهائل من البيانات الغير منظمة بحيث يصيسب الاســفادة مات منها رغم ما بها من قيمة كبيرة

(Jharotia, 2018)

ولما كانت المكتبـات -والقـائمين عليها - تعني بشـــأن البيـانات والمعلومات وعمليـاتها (تجميع وانتقاء وتنظيم وحفظ واســترجـاع وبـث ... الخ.) فلزم عليها -وعلى القـائمين عليها-

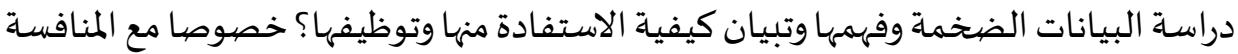

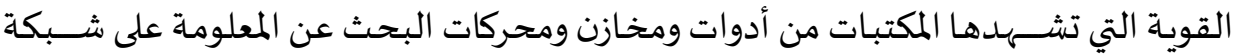

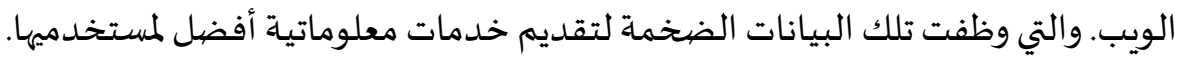

\section{ماهية البيانات الضخمة:}

قبـل البـدء بتعريف البيـانـات الضــخمـة يجبـ أن نعرف أولا مـاذا نعنى بـالبيـانـات؟

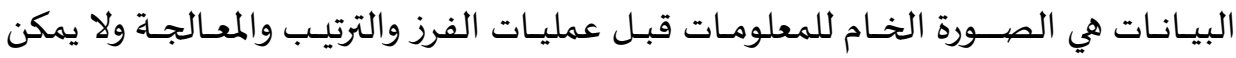
الاسـتفادة منها بصـورتها الأولية قبل المعالجة، كما عرف الشـامي البيانات بأهها عبارة عن تمثيل

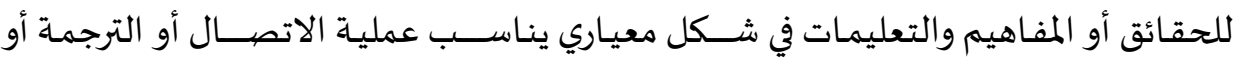

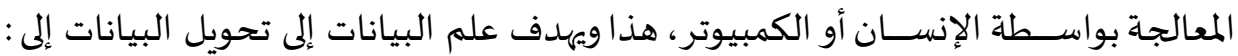

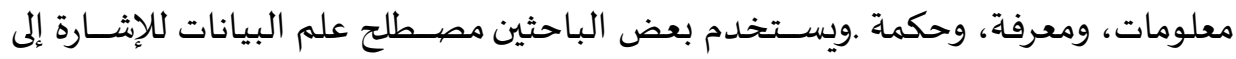

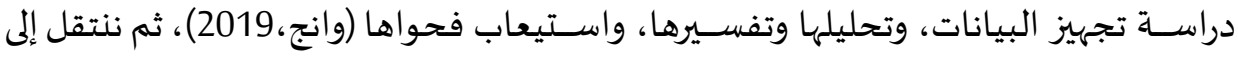

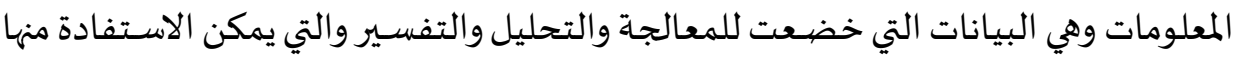
في استنباط العلاقات المختلفة بين الظواهر واتخاذ القرارات. 
وإذا انتقلنا للبيانات الضخمة ورغم انتشار المصطلح إلا أنه يوجد عدد كبير جداً من

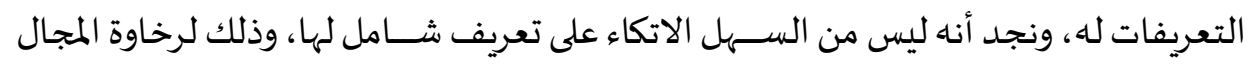

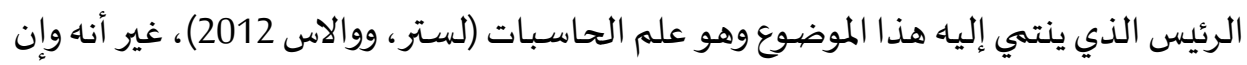

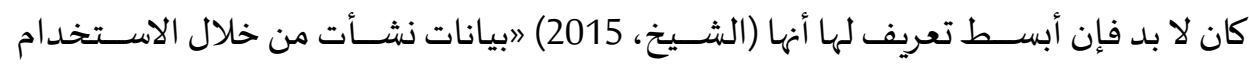

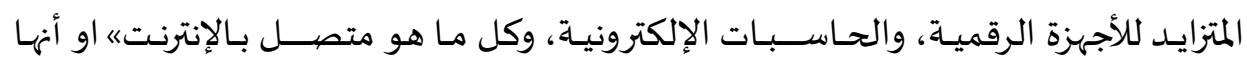

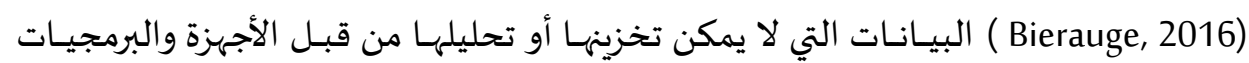
التقليدية "

كما يمكن تعريف البيانات الضشخمة بأها تنوع ضشخم من البيانات متعددة الأشكال

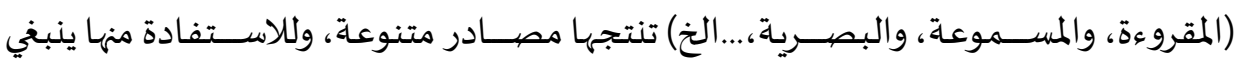

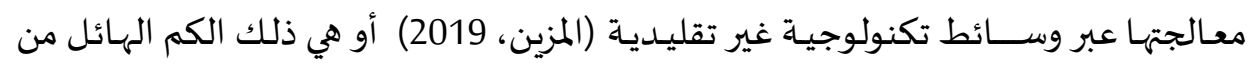

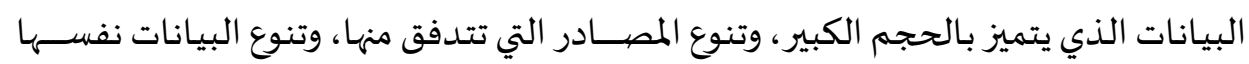

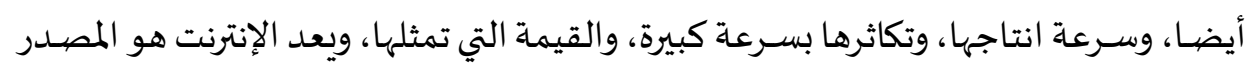

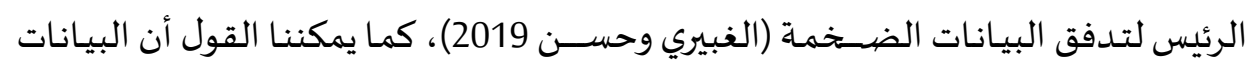

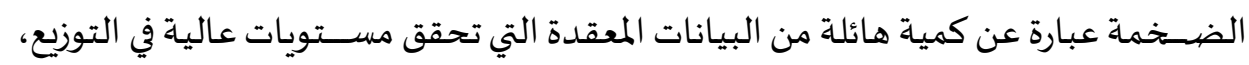

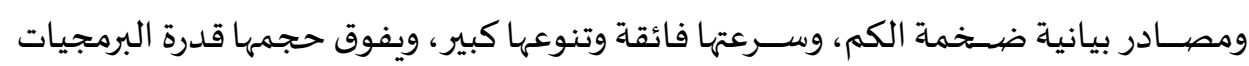

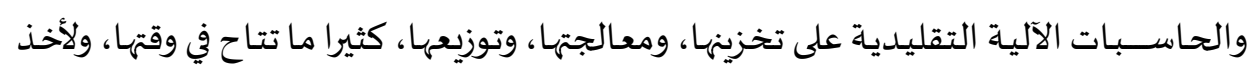

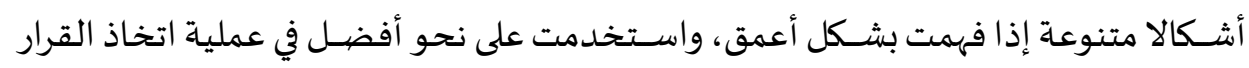

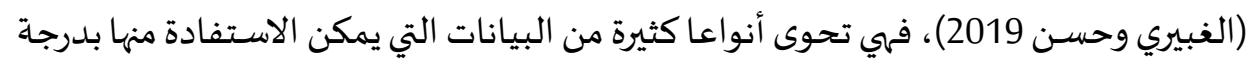

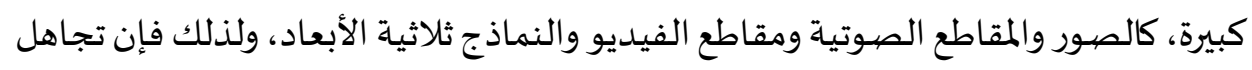

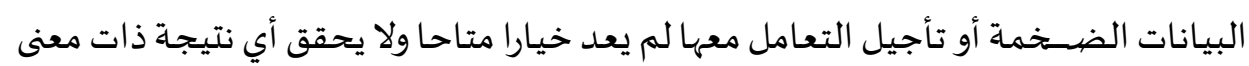
للمنظمات في ظل التنافس بينهم على المستهلكين (الكلبي، 2018). ونخلص مما سبق أن البيانات الضخمة هي مجموعة من البيانات كبيرة جدا ومعقدة

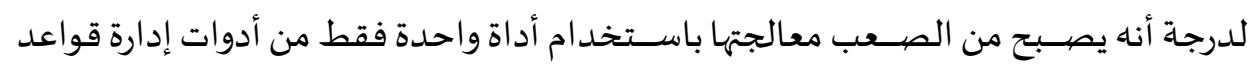

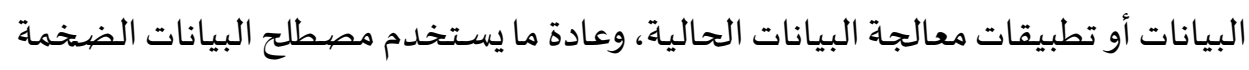

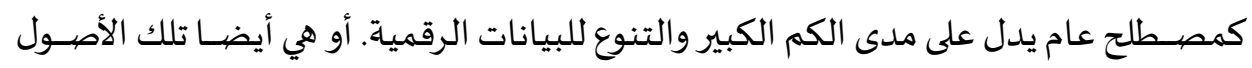


المعلوماتية التي تتميز بضخامة الحجم، والسـرعة الهائلة، والتنوع الكبير؛ والناشئة عن تطبيق

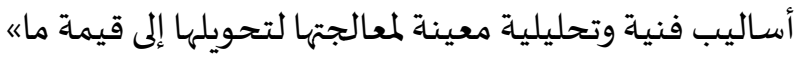

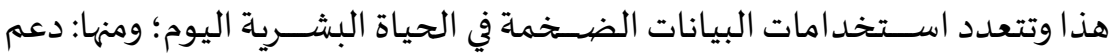

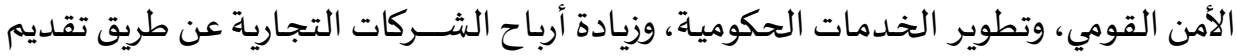

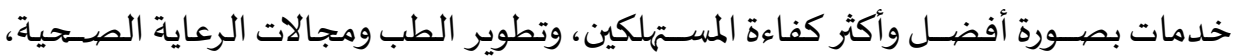

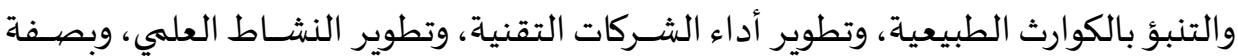
عامة الارتقاء بالحياة اليومية للمواطنين (فراج، 2018).

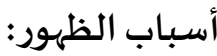

يعود سـبب النمو الســريع في إنتاج البيانات الضـخمة، لانتشـــار الأجهزة والأنظمة

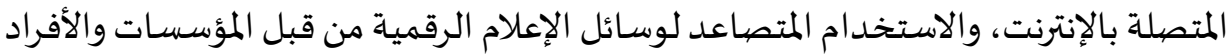

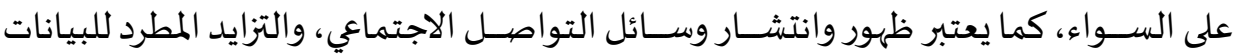
التجارية والاقتصادياة، وكذا بيانات البحوث العلمياة، تعد من أهم الأسباب وراء ظهور البيانات ولتهات الضـحمــا (Hassaneen, 2019) ، فمع تطور تقنيـات الإنترنـت التي أتـاحـت لجميع الأجهزة

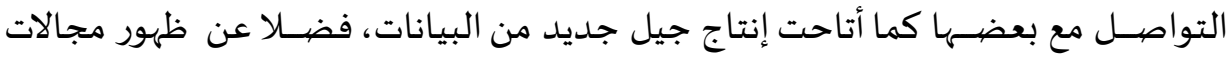

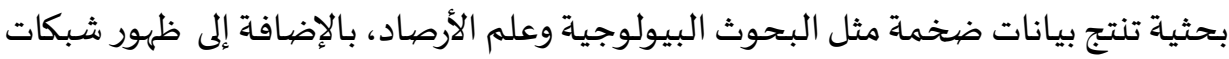

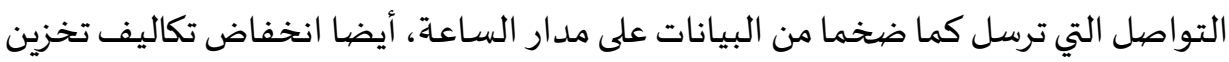

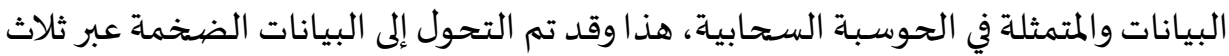
مراحل (المزين، 2019)، أولا الانتقال من الثقافة الورقية إلى الأوعية الرقمياة، وثانيا الانتقال

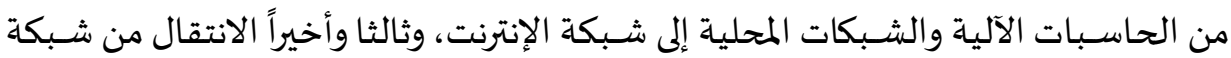

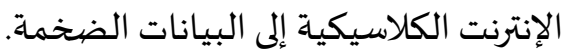

أهمية البيانات الضخمة:

قيمة البيانات تأتي من وفرتها التي تتزامن مع القدرة الفائقة في التعامل معها وتوظيفها

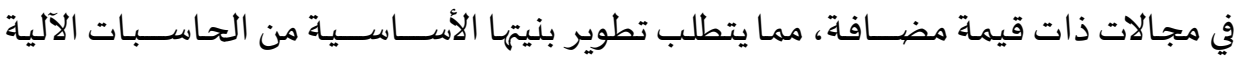

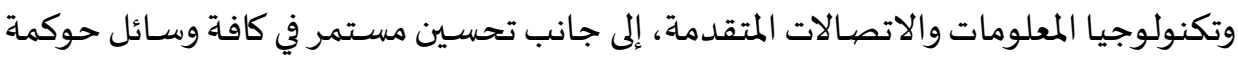


البيانات من خصـوصية وأمن البيانات وحمايتها من الاختراق، مع الاسـتثمار المجدي في المهارات

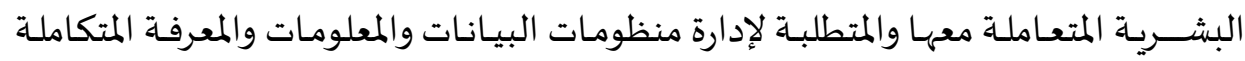

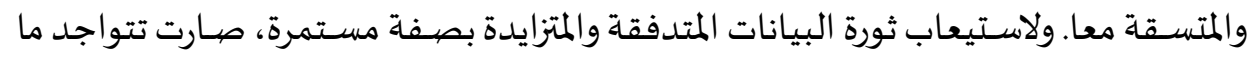

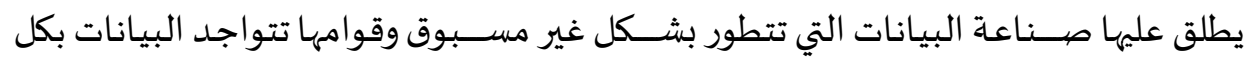

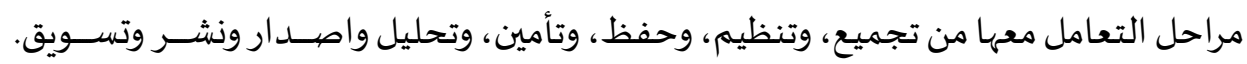

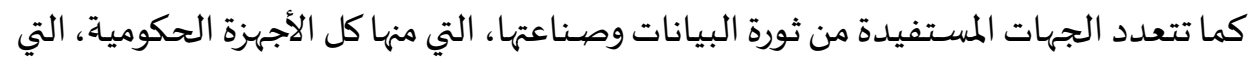

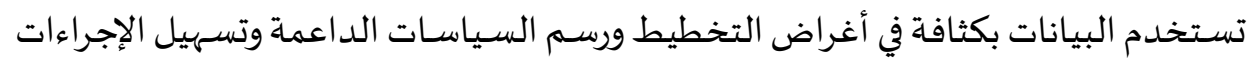

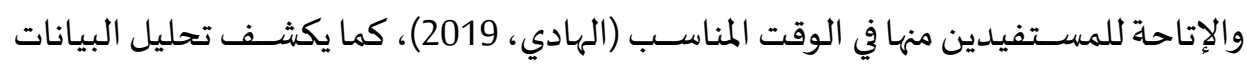

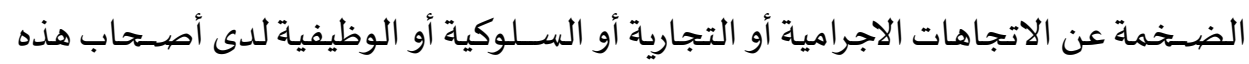

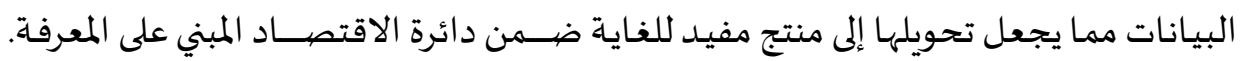

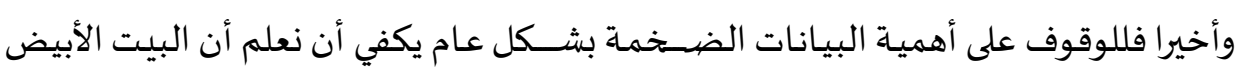

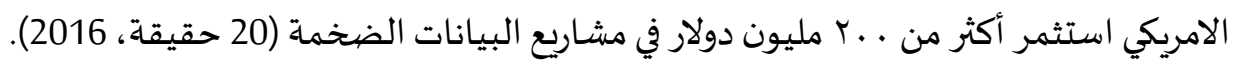

\section{خصائص البيانات الضخمة:}

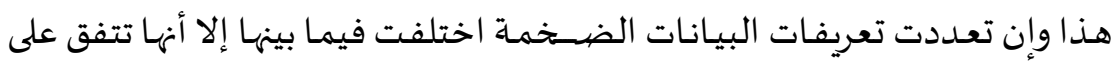

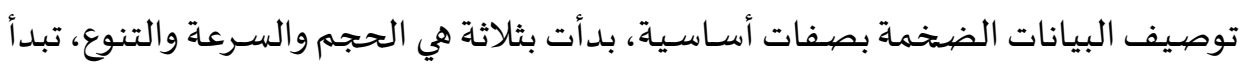

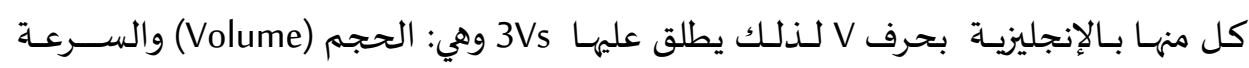
(Velocity)

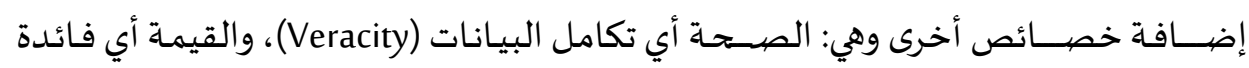

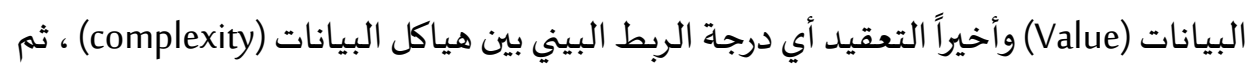

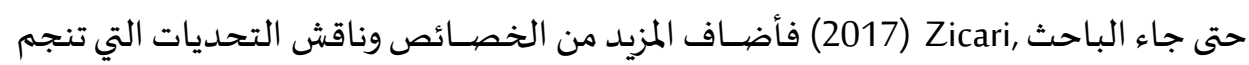

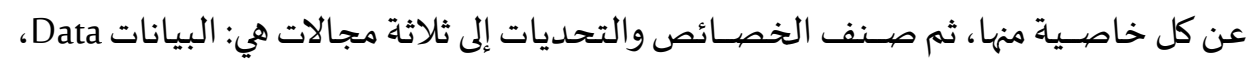

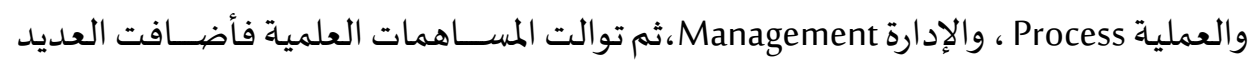

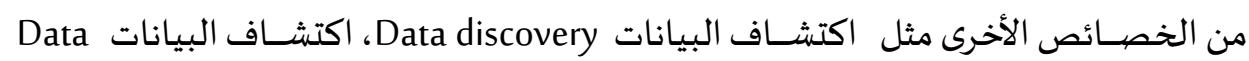
Data discovery 
Comprehensiveness

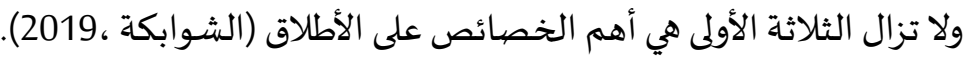

\section{أولا: الحجم Volume}

نعيش اليوم في عصـــ تتراكم فيه البيانات بشــكل كبير جدا كل لحظة، فلم يســق للبشـرية ان راكمت مثل هذا الكم من البيانات بأي شـكل من الأشـكال، فني كل يوم منذ عام عام

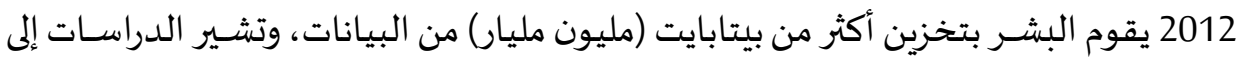

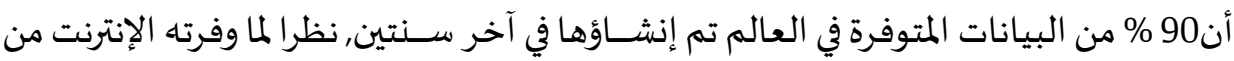
سـهولة لإدخال المعلومات ومشـاركتها وخزنها، وقد وصيل حجم البيانات المنتجات في العام 2015

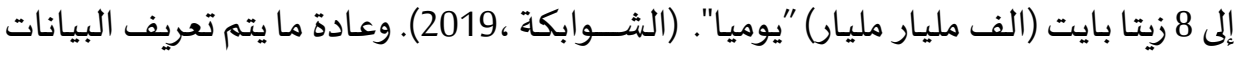

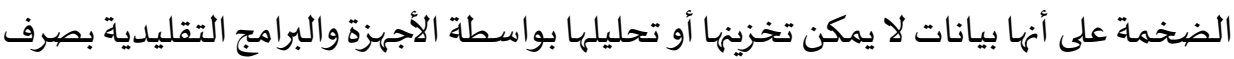

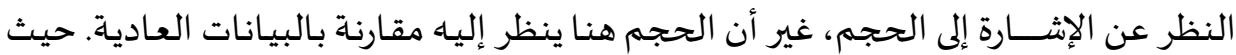

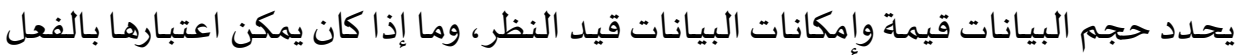

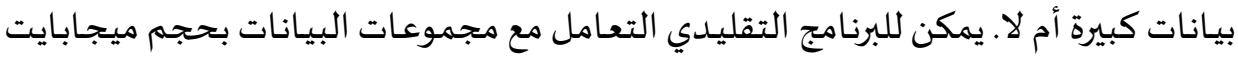

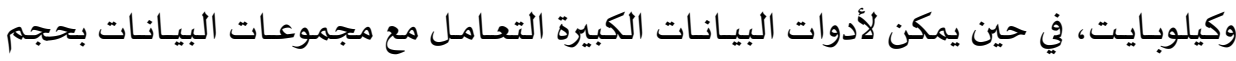

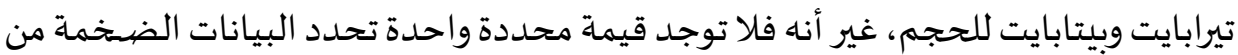

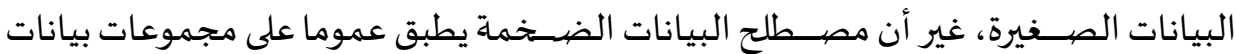
كبيرة بما فياه الكفاية بحيث لا يمكن استخدام تقنيات معالجة البيانات التقليدية للعمل عليها

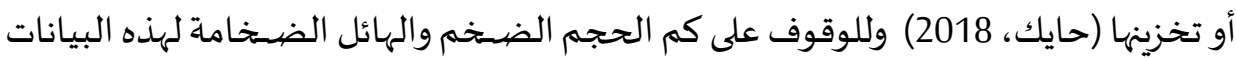
يمكننا الإشارة إلى ذلك في النقاط التالية :

- - يضاف 1.7 ميجابايت من البيانات الجديدة في كل ثانية لكل فرد على هذا الكوكب. - وصلت بيانات العالم الرقمي اليوم إلى حوالي 44 زيتابايت. - تحدث 1.3 ترليون عملية بحث سنوي على محرك البحث جوجل وحده. - موقع فيســبوك يتداول 31.3 مليون رســالة تقريبا. ويســعرض 2.77 مليون مقطع

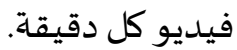
- يتم تحميل نحو . . س ساعة من مقاطع الفيديو في موقع يوتيوب كل دقيقة. 
- لدينا نحو 6.1 مليار مستخدم للهواتف الذكية.

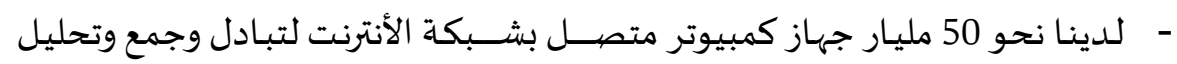

$$
\text { البيانات. (20 حقيقة، 2016) }
$$

- - ينتج تويتر أكثر من 7 تيرابايت من البيانات كل يوم ،

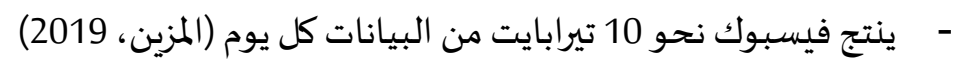

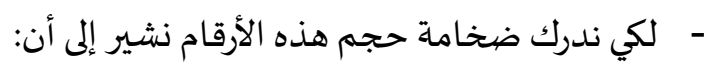

$$
1 \text { كيلوبايت kB = تقريبا } 103 \text { = تقريبا 1,000 بايت }
$$$$
1 \text { ميجابايت MB = تقريبا } 106 \text { = تقريبا 1,000,000 بايت }
$$$$
1 \text { جيجابايت GB = تقريبا } 109 \text { = تقريبا 1,000,000,000 بايت }
$$

1 تيرابايت TB = تقريبا 1012 = تقريبا 1,000,000,000,000 بايت

1 بيتابايت PB = تقريبا 10 $10^{15}$ =قريبا 1,000,000,000,000,000 بايت

1 إكسابايت EB = تقريبا 10 = تقريبا 1,000,000,000,000,000,000 بايت

1 زيتابايت ZB = تقريبا 1021 = تقريبا 1,000,000,000,000,000,000,000 بايت (بيت،

(2020

غير أن التقنيـات الحـديثة قـد أســهمت إلى حـد كبير في الكثير من حلول مواجهـة

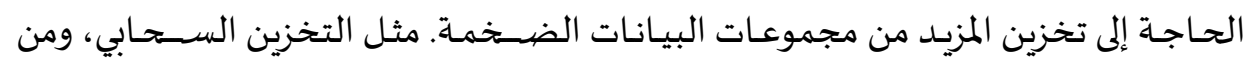

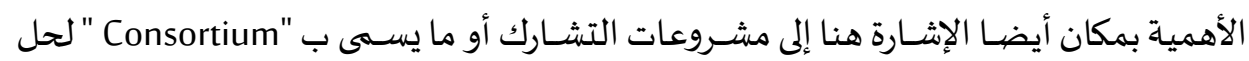

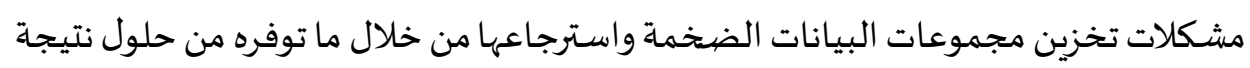
ارتباط مئات أو آلاف من أجهزة الحاسب والخوادم معاد معا (عبد الله وسعيد، 2018)

ثelocity تانيا: السرعة

وهي تناقش الســرعـة المذهلة التي يتم بها إنشـــاء البيانات ومعالجتها لتلبية طلبات

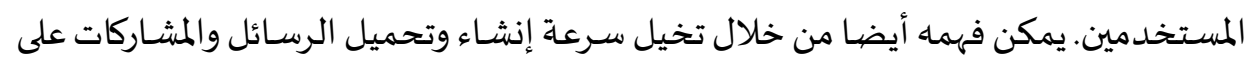

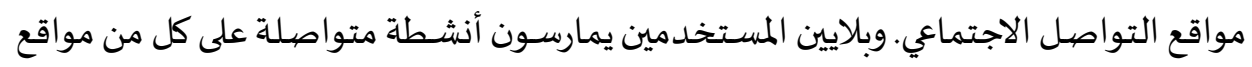


التجارة الإلكترونية، المدونات، الشبكات الاجتماعية، التي تنتج تدفقات بيانات لحظية مستمرة

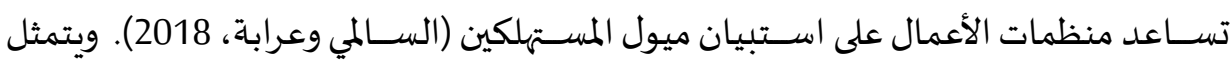

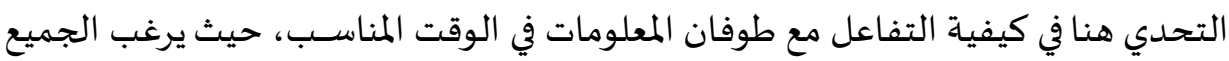
في الوصول إلى البيانات في الوقت المناسب (المزين، 2019).

\section{ثالثا: التنوع Variety}

فتحتوي مجموعات البيانات الضخمة على بيانات متفرقة مثل التغريدات على تويتر،

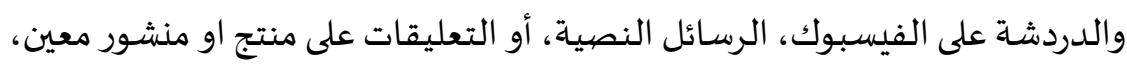

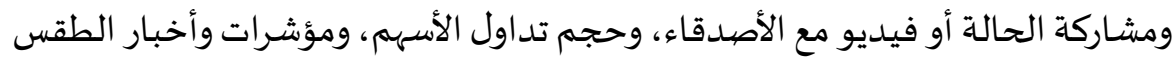

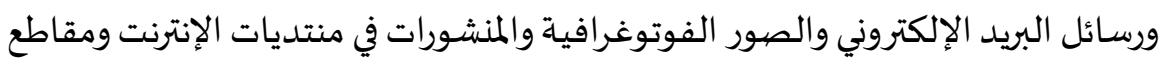

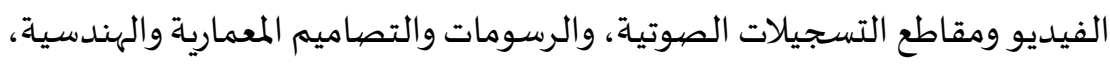

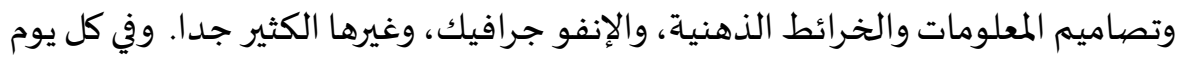

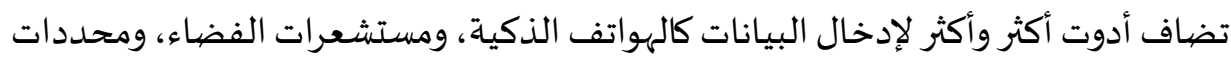
المواقع الجغرافياة، وبيانات السير والمرور، ومدخلات معلومات التلاميذ والطلاب والموظفين المانين

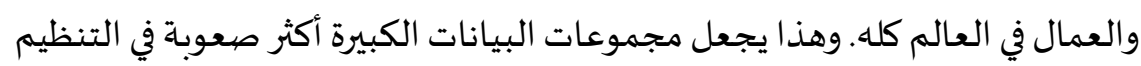

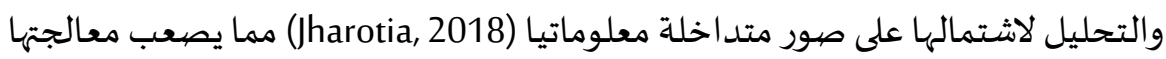

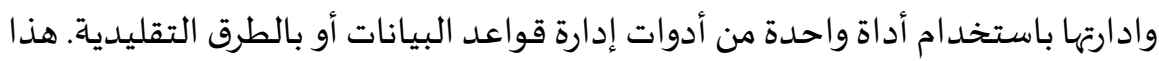

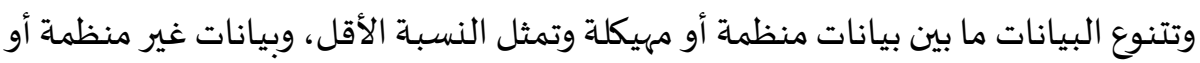

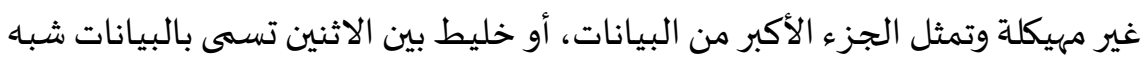
المنظمة أو المهيكلة (عبد الله وسعيد، 2018) و(السالمى وعرابة 2018).

- البيانات المهيكلة: البيانات المنظمة في صهورة جداول أو قواعد بيانات تمهيدا لمعالجتها.

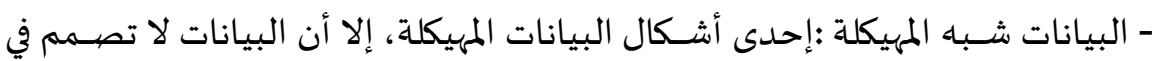

$$
\text { جداول أو قواعد بيانات. }
$$

- البيانات غير المهيكلة :البيانات التي ينشئها الأشخاص يوميا من كتابات نصية، وصيور،

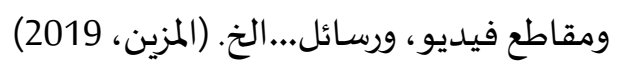


وبهذا يتضهح أن التحـدي يظهر في كيفيـة التعامل مـع الأنواع والمصيـادر

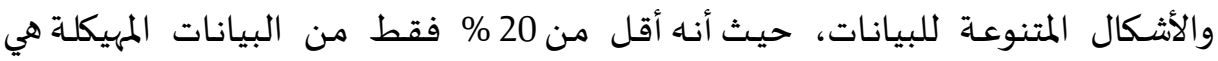
التي يمكن أن تعالج بواسطة الأنظمة التقليدية (المزين، 2019)

رابعا: القيمة Value التي ترتبط بالبيانات الذكية Smart Data التي تتمثل في القيم المستنتجـة من البيانات الكبيرة الصحيحة المتاحة (السالمى وعرابة 2018). ففي البداية اقتصر تحليل مجموعات البيانات

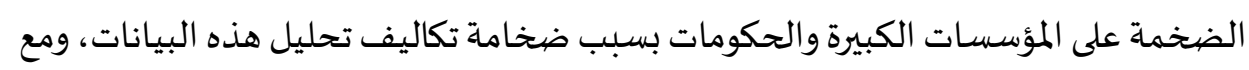
الوقت نتيجة للتطور التقني وتوافر وخفض تكلفة الأجهزة والبرمجيات، فقدل تداول تحليل

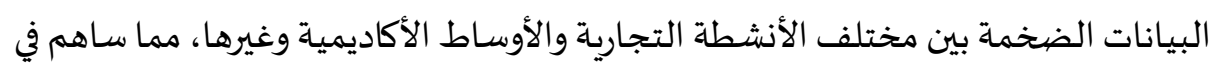
توجيه هذه الأنشطة نحو خفض التكلفة، تطوير منتجاتها وتحسين المعروض، صنع القرار

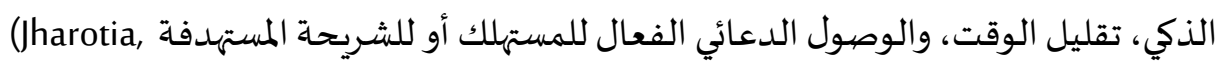

\section{خامسا المصداقية Veracity}

يتم التعبير عن المصسـاقية في التأكيد على أهمية ضــمان موثوقية وسـلامة البيانات.

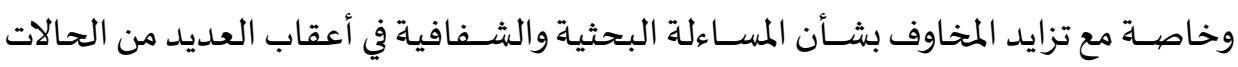

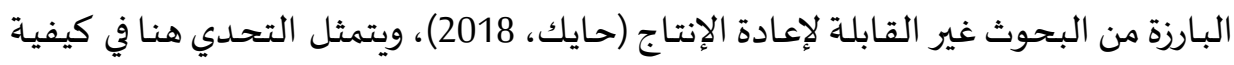

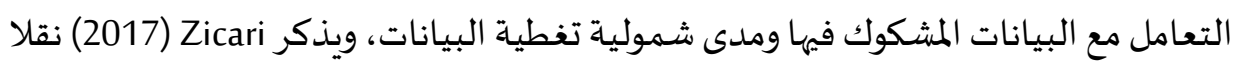

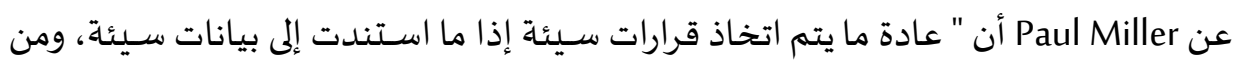

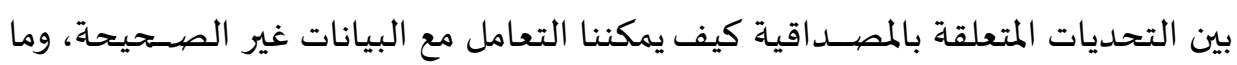

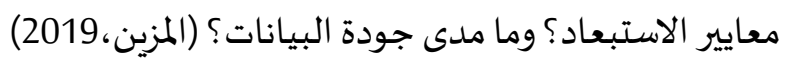

مما سبق يمكن القول أن هذه الخصائص قد فرضت شكلاً جديداً من طرق التعامل

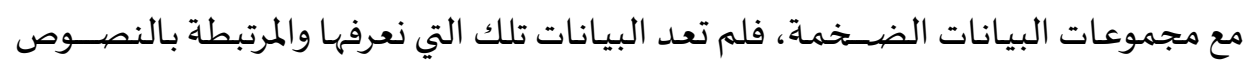

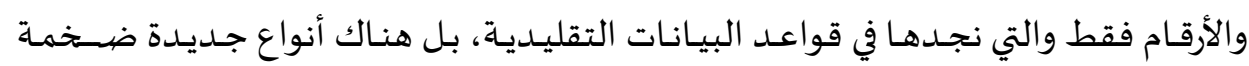

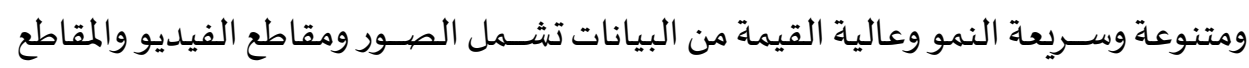


الصــوتية، والنماذج ثلاثية الأبعاد وبيانات المواقع الجغرافية وغيرها (حبش، د.ت). وهنا نصـل

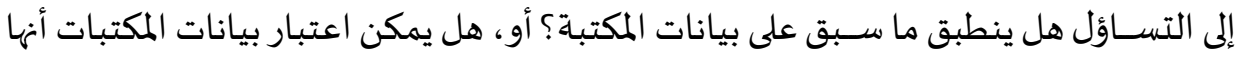

بيانات ضخماة؟

هل يمكن اعتباربيانات المكتبات أهها بيانات ضخمة؟

تجيب دراستين للشـوابكة على هذا التسـاؤل (الشـوابكة، 2019)، (الشـوابكة، 2018)

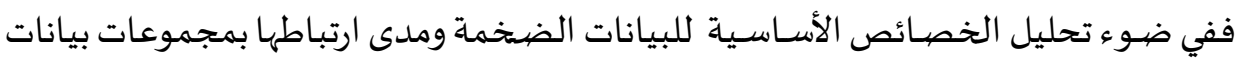

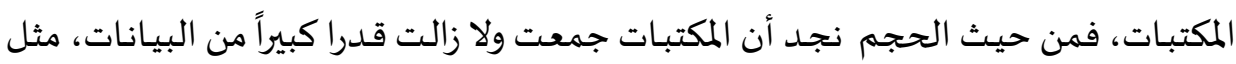

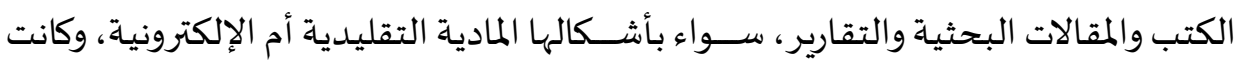

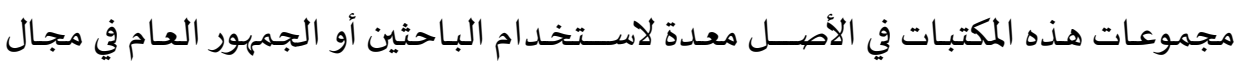

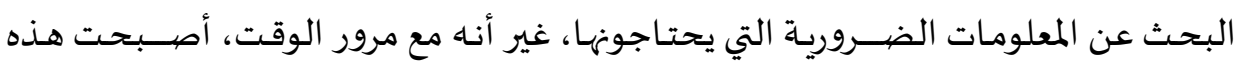

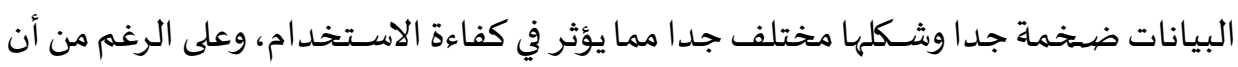

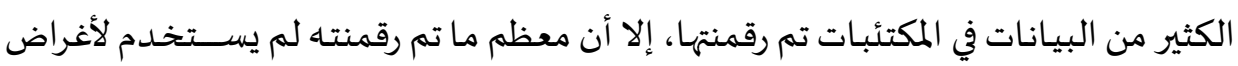

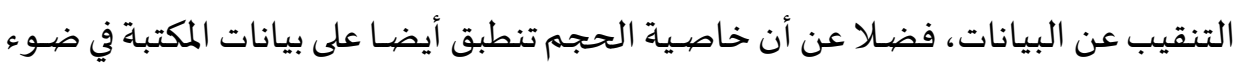

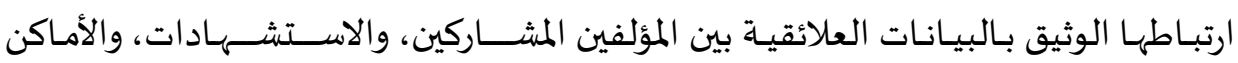

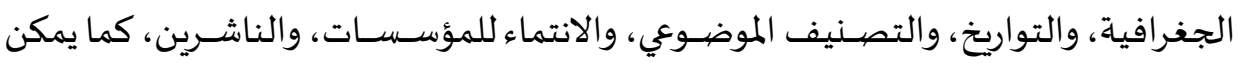
أيضا للمكتبة جمع البيانات التي يبحث عنها المستفيدون والتوانيف والباحثون.

وأما الســرعة فيمكن العثور على خصــائص ســـرعة البيانات الضــخمة في بيانات

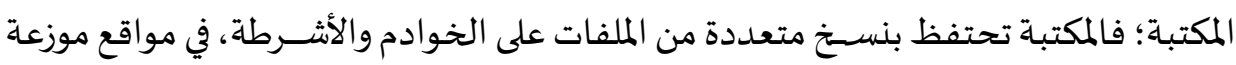

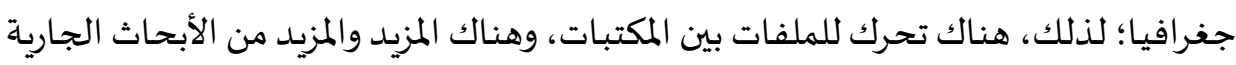

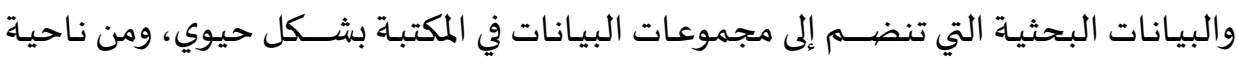

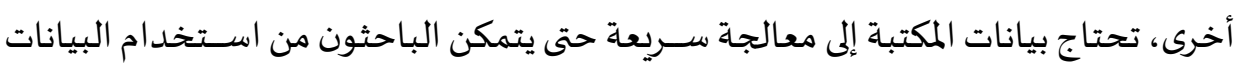

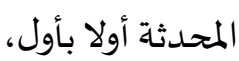

ومن حيث التنوع، فإن المكتبات تقتني أنواعا مختلفة من البيانات: كالكتب والمجلات

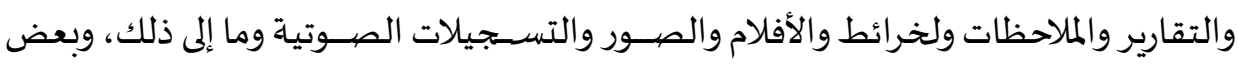

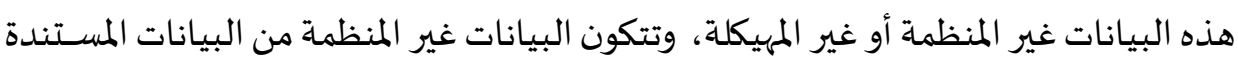


إلى اللغـة (مثل الملاحظات ورســائل تويتر والكتب) ومن البيانات غير المعتمدة على اللغة (مثل

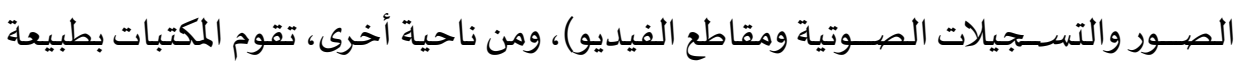

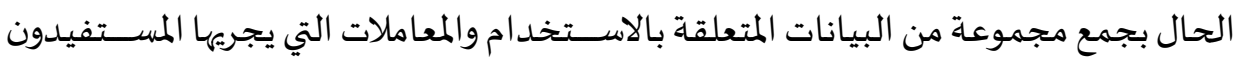

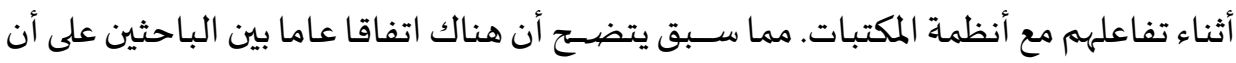

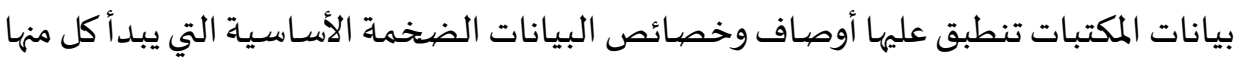

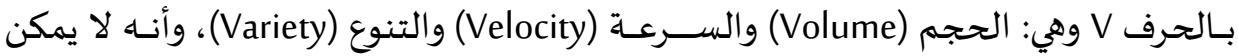

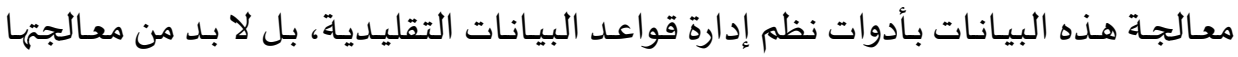

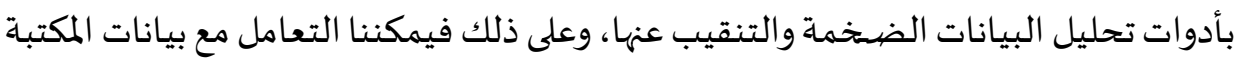
كبيانات ضخمة دون شك وذلك بسبب مقتنياتها ذات الحجم الضخم والسرعة العالية والتنوع الواضح.

مصيادر البيانات الضخمة بالمكتبة: تعتمد المكتبة على مصـادر متعددة ومتنوعة للحصيـول على البيانات، وتعد قواعد

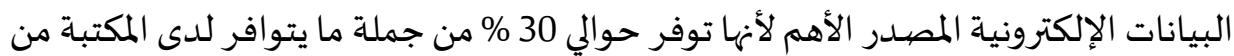

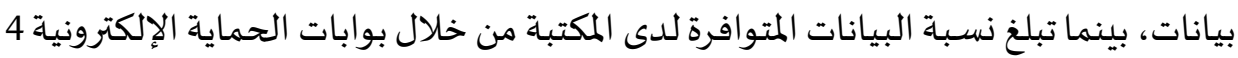

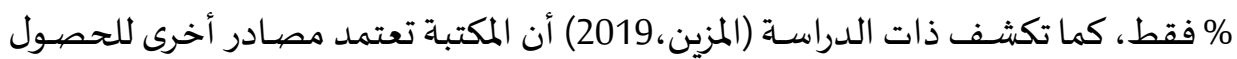

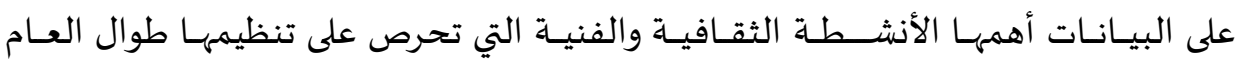

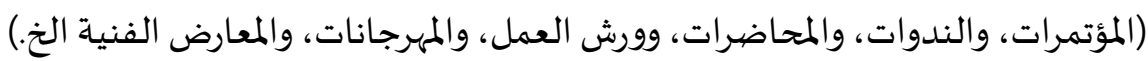

\section{تفعيل الاستفادة من البيانات الضخمة}

لكي نســــيع الاســـفـادة من البيانات الضــخمة لا بـد من مشـــاركة ثلاثة أطراف

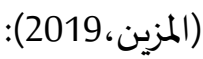

\section{أولا موفر البيانات الضخمة:}

يعمل موفر البيانات الضشخمة على توفير البيانات من مصيـادرها المختلفة إلى مقدم

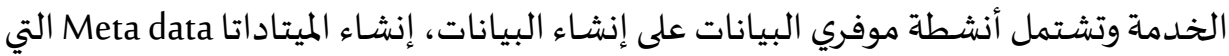


تصـف مصيدر البيانات، إيجاد مصيادر البيانات المفتوحة على الإنترنت، توفير بيان الخدمات

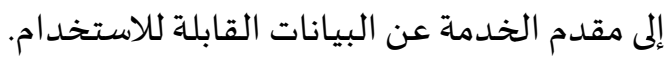

\section{ثانيا مقدم خدمة البيانات الضخمة.}

يقوم مقدم الخدمة بتحليل البيانات الضخممة وتوفي البنية التحتية اللازمة لها، ومن

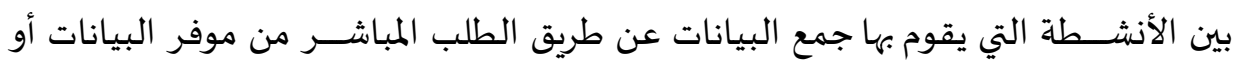

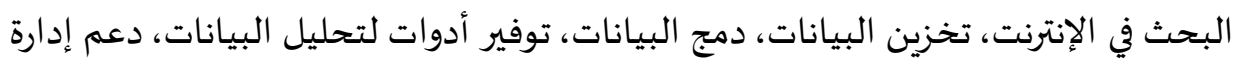
البيانات مثل خصوصية البيانات وأمن البيانات

\section{ثالثا: عميل خدمة البيانات الضخمة.}

يقصيد باه المستخدم النهائي لمنظومة البيانات الضخمة سـواء كان شخصـا أم نظاما،

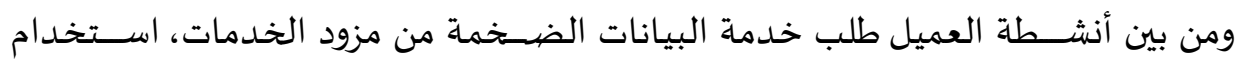
مخرجات خدمة البيانات الضخمة.

مما سـبق يمكننا القول إن منظومة البيانات الضـخمة لا تؤتي ثمارها إلا بتضـافر جهود جميع الأطراف المشـاركة في المنظومة، فما الفائدة من الاحتفاظ بأي قدر من البنات البيانات

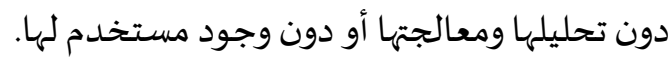
متطلبات المكتبات للاستفادة من مجموعات البيانات الضخمة: وهي مجموعة من العناصر المطلوب توافرها في المكتبات، لتتيح لها الفرصة لاستخدام

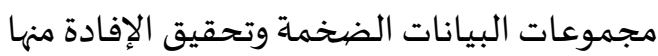

أولا: قدرات ومهارات العاملين بالمكتبة للتعامل مع البيانات الضخممة: تعتبر الموارد البشـرية العنصـر الأهم سـواء في المكتبة بشـكل عام أو في إدارة البيانات

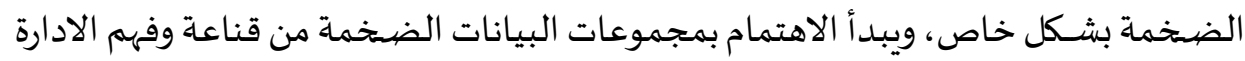

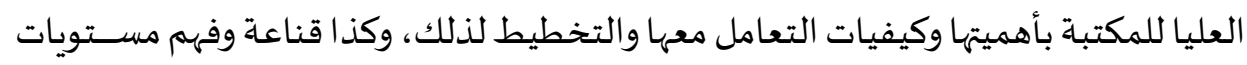
المختلفة الأخرى بالتنفيذ والمتابعة. ثم بقدرات ومهارات العاملين أنفسهم لأداء هذه الإجراءات، واتهات

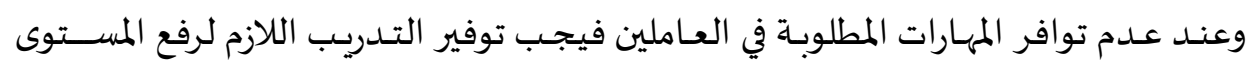




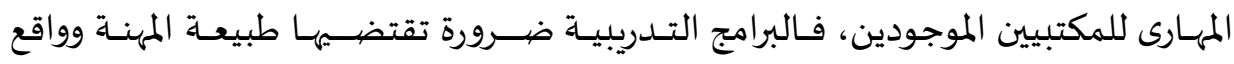
المعلومات المتجدد، وعند توفر الميزانيات اللازمة يمكن دعم المكتبة بعدد من الأخصائيين المهرة

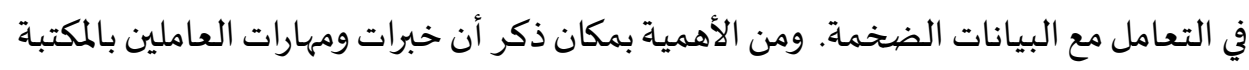

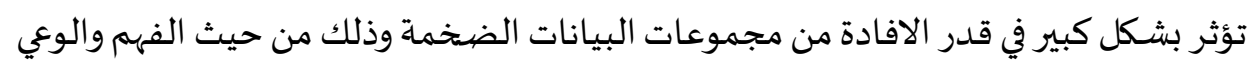

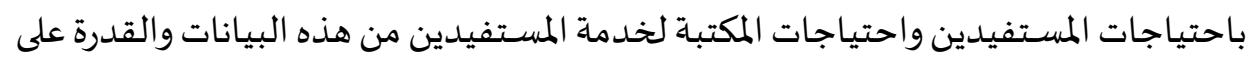

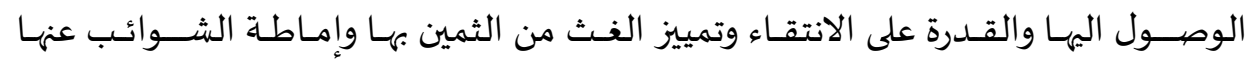

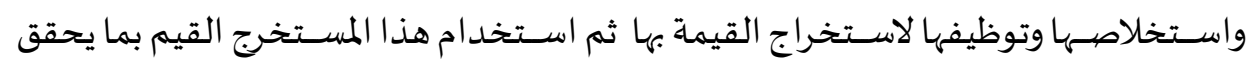

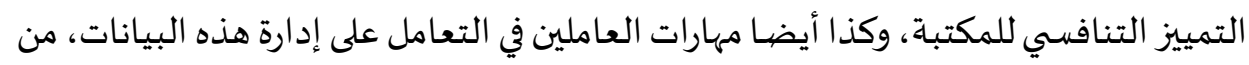

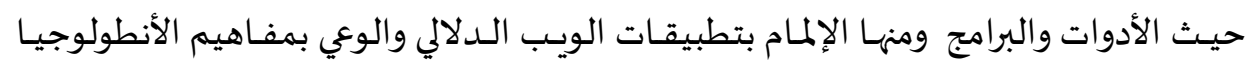

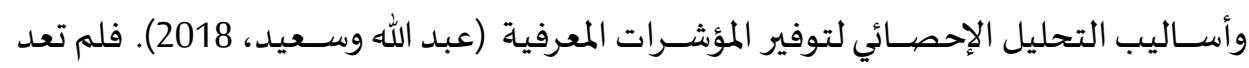

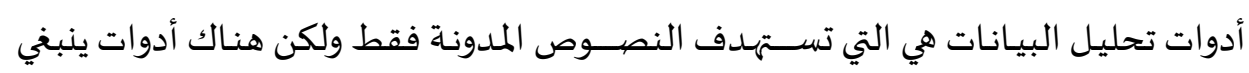

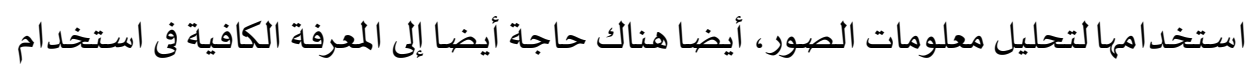

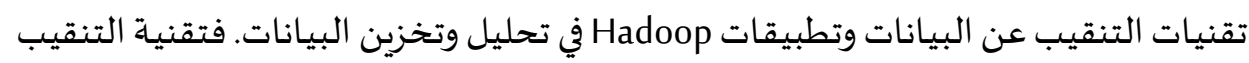

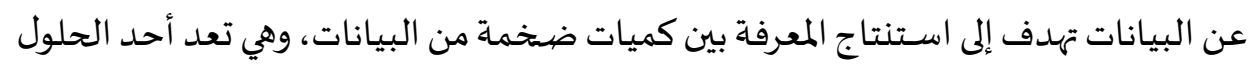

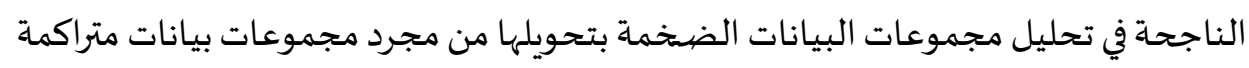

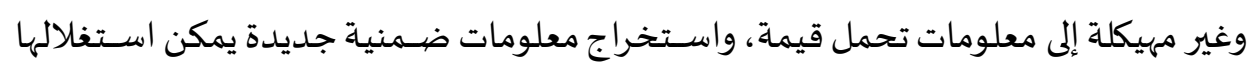

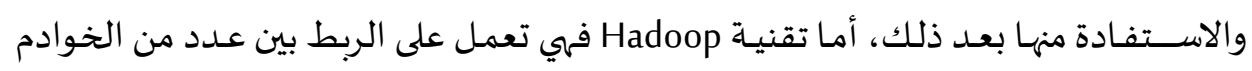

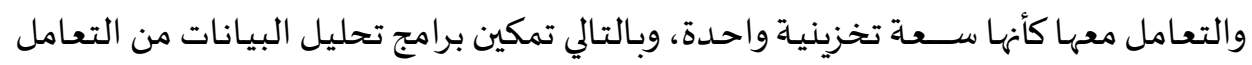
معها والاستفادة منها (حايك، 2018)

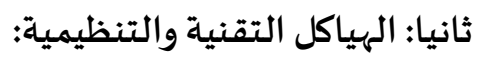
وتتعلق بقدرات الحواسـب والشـبكات و البرامج على تجميع و حفظ وتحليل البيانات

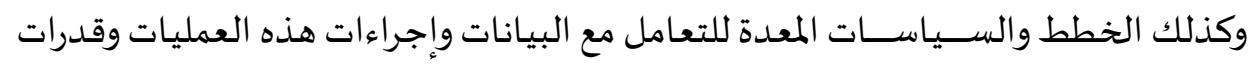

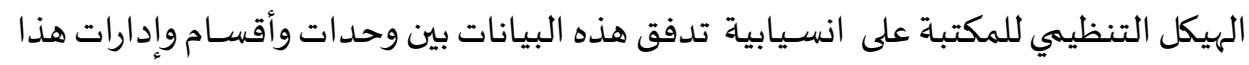

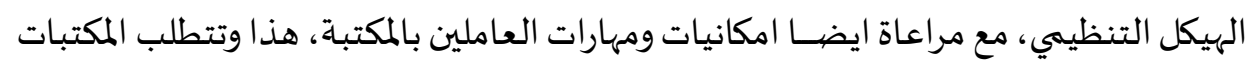

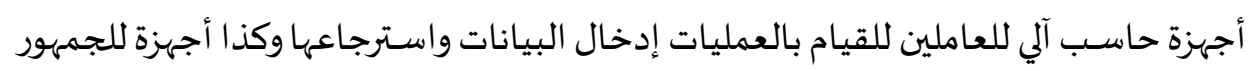


للتعامل مع الانترنت وفهرس المكتبة، ويجب أيضـا توفير الخوادم اللازمة لتشـغيل البرمجيات

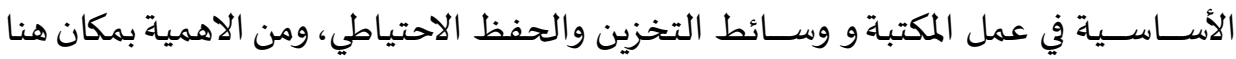

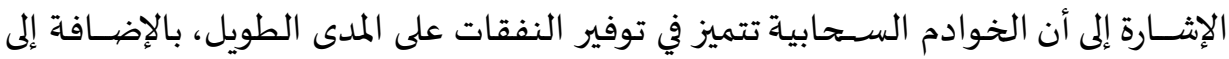

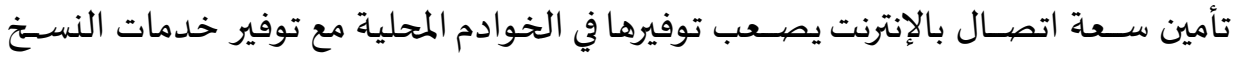

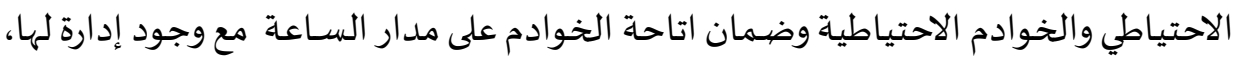

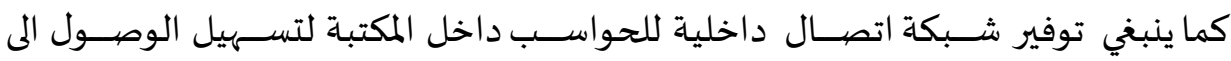

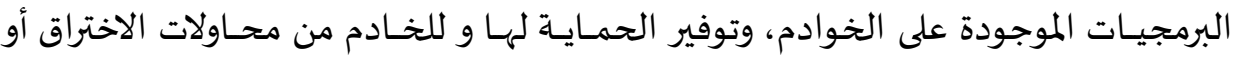

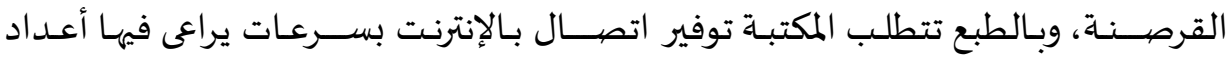

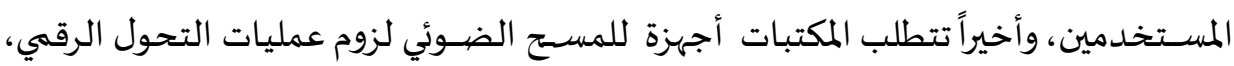

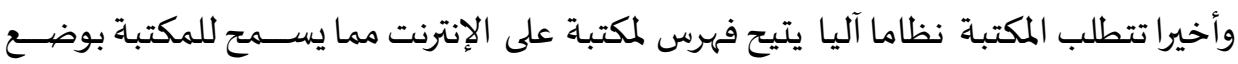
قدمها ضمن مجتمع المعرفة (الزلباني، 2019) ثالثا: جمع وحفظ مجموعات البيانات الضخمة: ويتعلق الأمر هنا بتقرير البيانات الهامة والتي تصــب في دعم اتخاذ القرار الصــائب

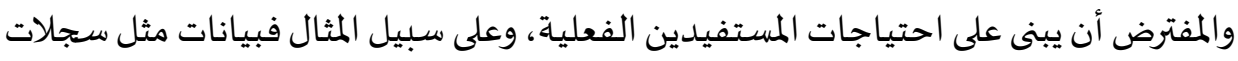

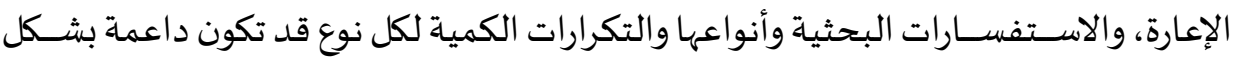

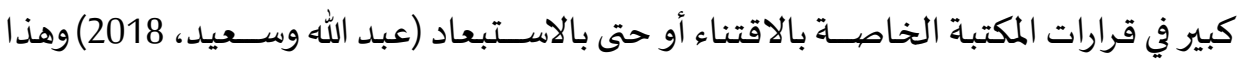

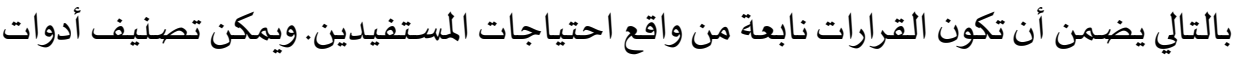

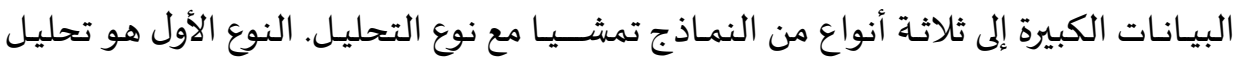

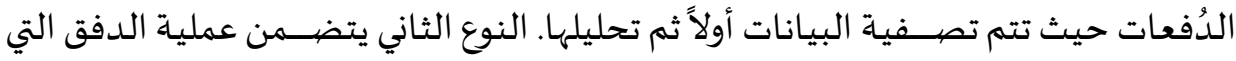

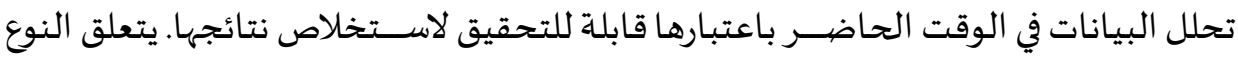

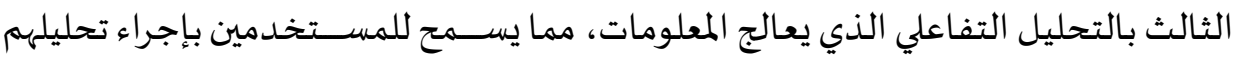
الخاص للبيانات (2018 Al-Karousi \& Al-Barashdi)

1. أدوات البيانات الكبيرة لتحليل الدفعات: ومن أشــهرها ( Google MapReduce و Apache Mahout. Google و Microsoft Dryad و Apache Hadoop (MapReduce 
2. أدوات البيانات الكبيرة لتحليل الدفق: ويتطلب ذلك وجود أطر نظرية وفنية فعالة

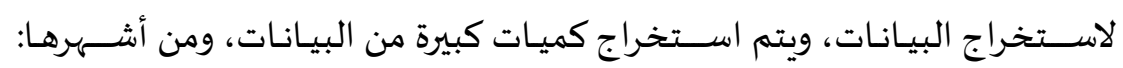

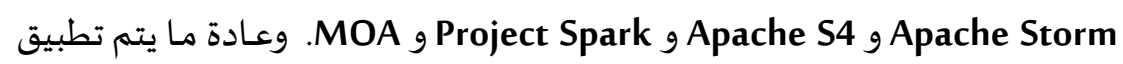
ذلك في التحليل المالي والتداول عبر الإنترنت والاختبارات الطبية. 3.

\section{D3 و D و D Dagoll}

أوجه الافادة من البيانات الضخمة في المكتبات: (Jharotia, 2018)

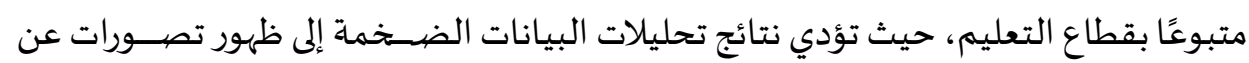

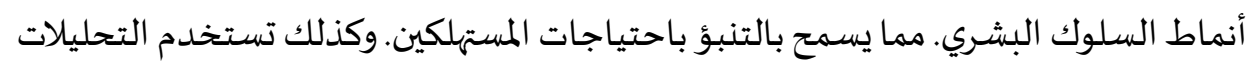

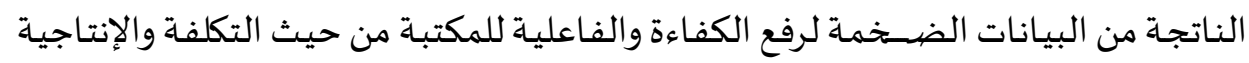

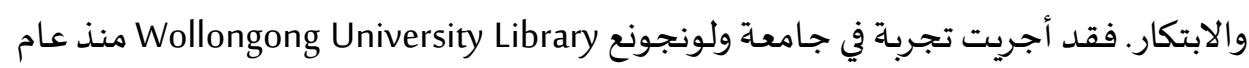

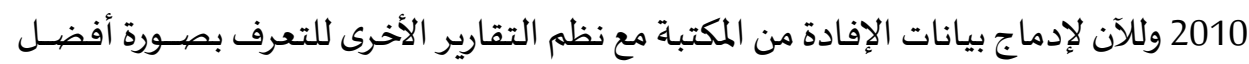

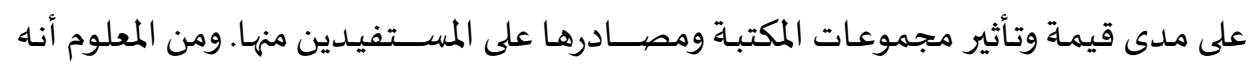

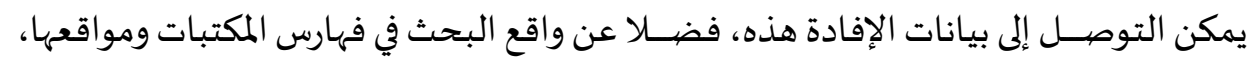

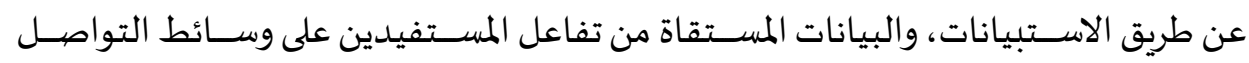

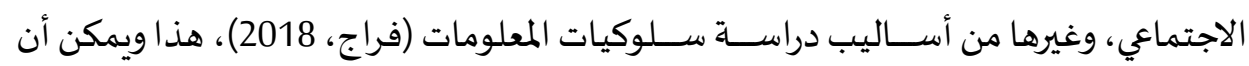

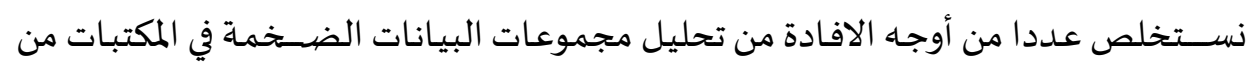

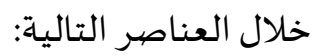

أولا : تعزيز ودعم الهيكلة الإدارية أو إعادة الهيكلة الإدارية (هندرة المكتبة) : تقدم مجموعات

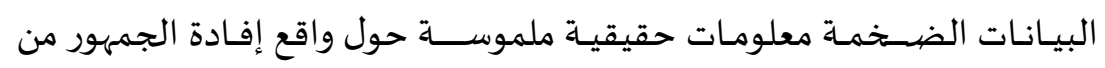

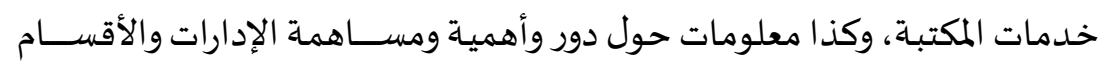

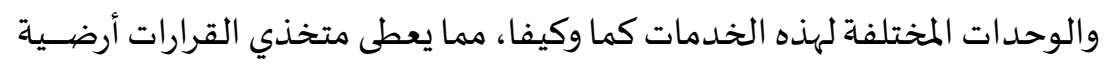

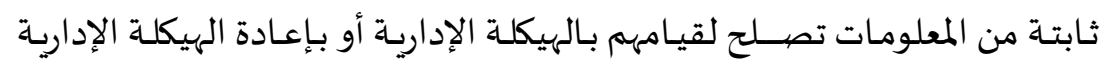

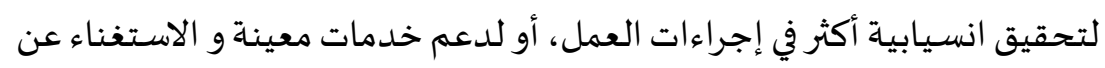


أخرى، أو لاسـتحداث خدمات جديدة مما يعمل على تنشـيط وتفعيل دور المكتبة،

$$
\text { مع تقليل الوقت والجهد والمصروفات في آن الن واحد. }
$$

ثانيا : إدارة خدمات وأنشـــة المكتبة : تسـتخدم مخرجات تحليل البيانات الضـخمة في تقييم

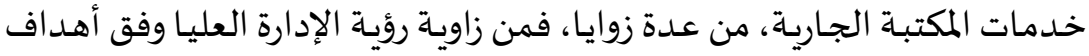

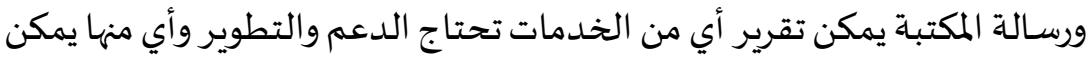

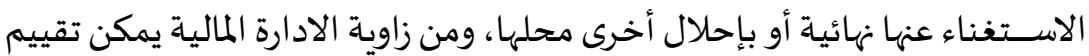

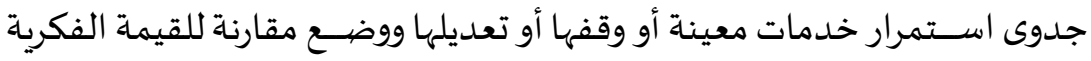
للخدمة كيفا وعدد ما قدم في هذه الخدماة فعليا كما مقابل التكلفة الإجمالية التي

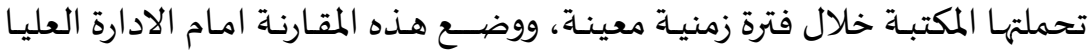

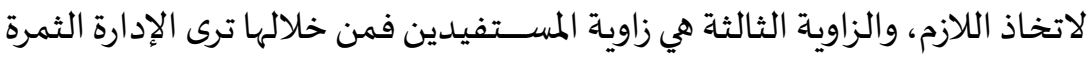

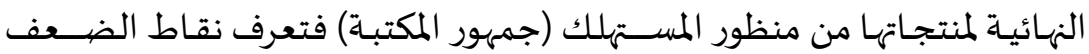

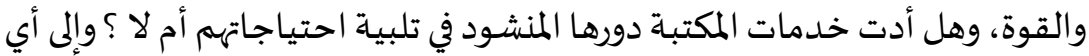

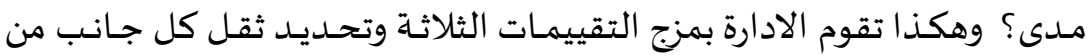
جوانب التقييم لتتخذ من ذلك القرار المناسب.

ثالثا: خفض تكلفة تشغيل المكتبة الكلية: ونتيجة لاتضاح الرؤى في كثير من الأمور يمكن لإدارة

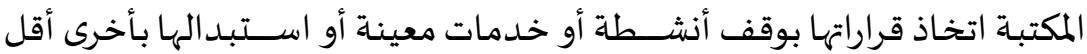
تكلفة، كما تقدم البيانات الضــخمة معلومات تســتخدم في التخطيط الصــحيح لأوجاه صرف الميزانية وترشيد بعض أوجه الصرف أو توفيرها لجوانب جديدة البدات رابعا: قواعد بيانات المستفيدين: تقوم المكتبة بعمل ملف بيانات وحساب خاص لكل مستفيد،

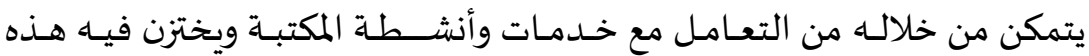

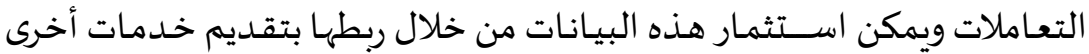
مثل الإحاطة الجارية والبث الانتقائي للمعلومات، ودراســات ســلوك المســفـيدين تجاه مجموعـات المكتبـة كما يمكن تقديم بيانات مجمعـة عن ذلك للبـاحثين مثل الدراسات الاحصيائية والاستقصائية وبيانات الإعارة وغيرها. 
خامســا: الموارد البشــرية: تمتلك المكتبة بيانات عن العاملين بها من متوســـطات الاعمار وكمم

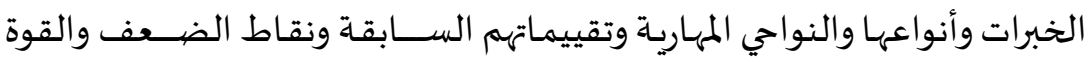

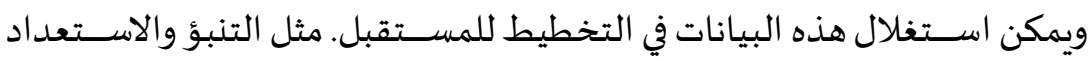

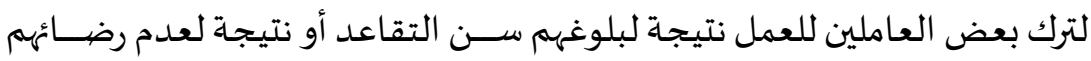
الوظيفي أو نتيجة لأن قيمة رواتههم السوقية أعلى مما يتقاضيونه في المكتبة.

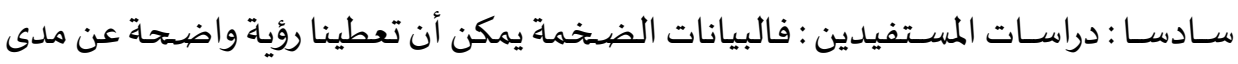

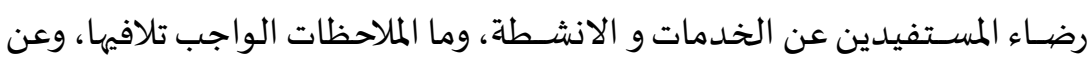

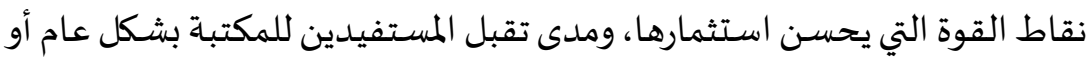

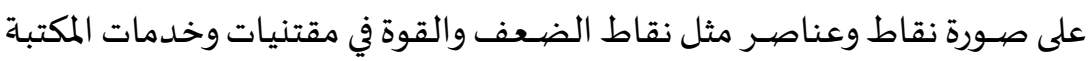

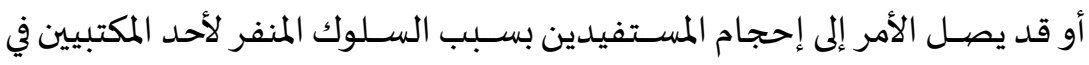

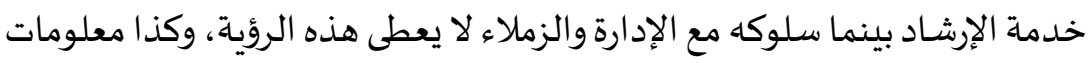

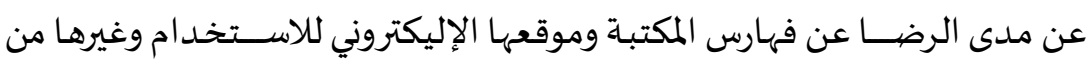
التحليلات التي يمكن الاستفادة منها (فراج، 2018).

ســابعـا: إدارة مجموعـات المكتبـة من المواد: كمـا يمكن للمكتبـة معرفـة الثفرات في مقتنيـات

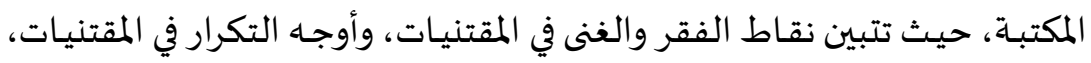

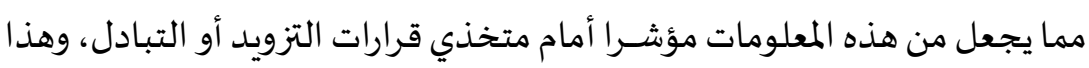

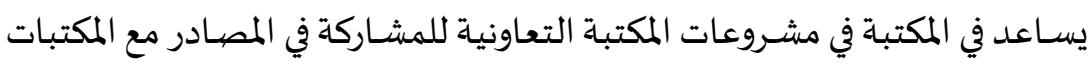
الأخرى.

\section{الرؤية الاستشر افية للإفادة من البيانات الضخمة في المكتبات:}

وفضـــلا عما ذكر عاليا من أوجه الافادة من البيانات الضــخمة في المكتبات، فيمكن

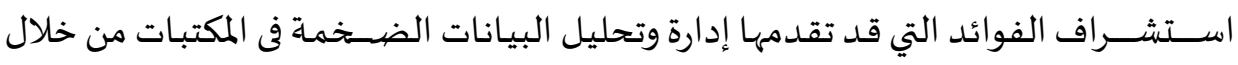
مناقشتنا للعناصر التالية (الكلبي، 2018): 1. رفع الكفاءة والفاعلية لاستغلال الموارد المتاحة للمكتبة بصورة أمثل. 
2. اكتشاف الفرص غير المستغلة واكتشاف مواضع الاهدار مما يسهم في توفير الجهد

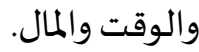

3. تحسين العمليات وتقديم خدمات وأنشطة أفضل لرضاء المستفيدين مما يعزز من دور وصورة المكتبة في مجتمعها. 4. اتخاذ قرارات مبنية على واقع، مما يرفع نسبة أن تكون القرارات صائبة. 5. زيادة القدرة على التميز التنافسي للمكتبة بين أقرانها.

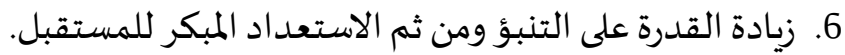

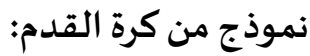

Liverpool's "قامت إدارة البحوث في ليفربول، أو كما يطلق عليه "فريق علم البيانات

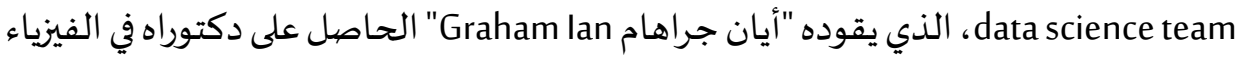
النظرية من جامعة كامبريدج، مع كلٍّ من "تيم واسكيت Tim Waskett" عالم الفيزياء الفلكية،

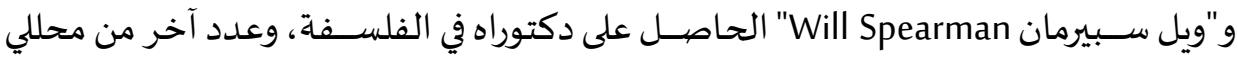
البيانات. تحليل البيانات الضسخمة Big Data، فقد قدّم فريق علم البيانات مفهوم السـيطرة

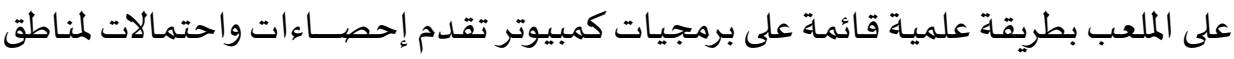

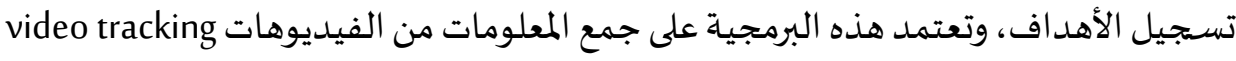

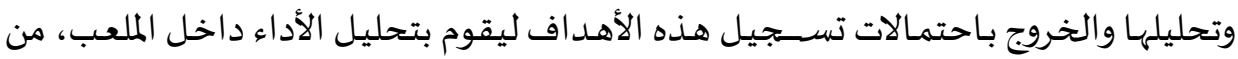

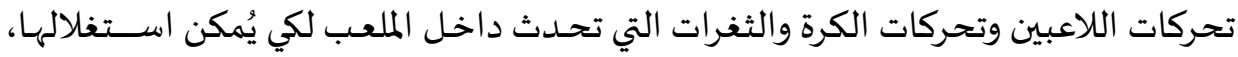

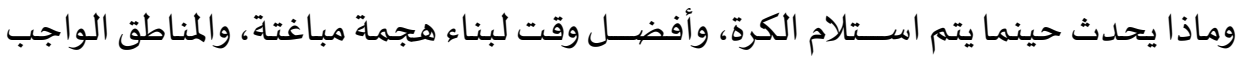

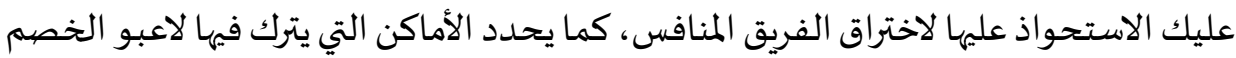

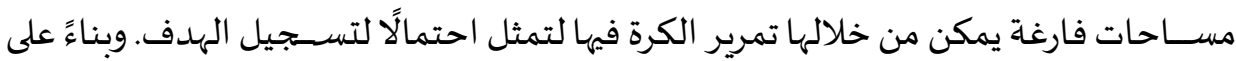

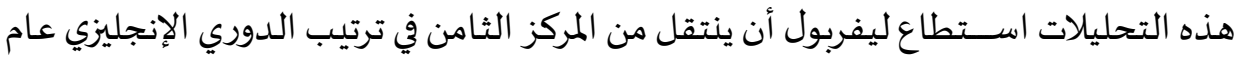

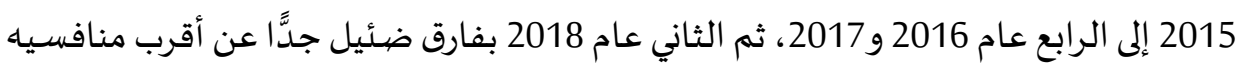

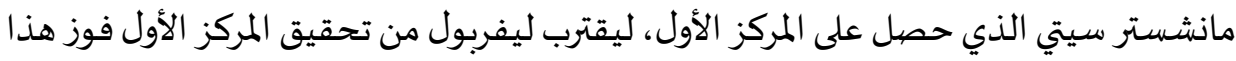

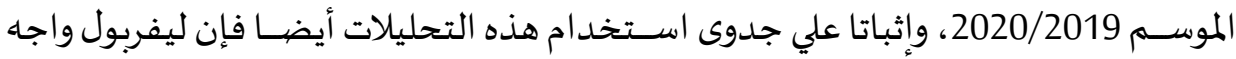


هذا الموسـم 55 تصيويبه علي مرماه، متفوقا على تشيلسي الذي واجه 65 تصـويبه ومانشسـتر -

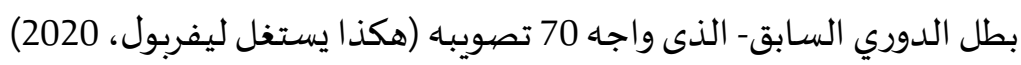

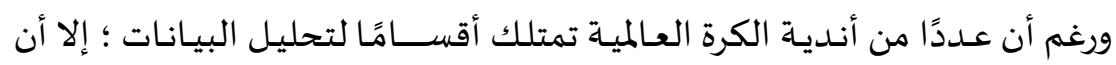

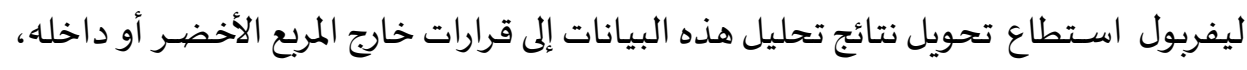

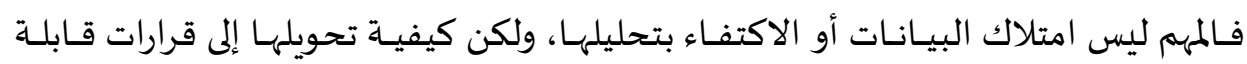

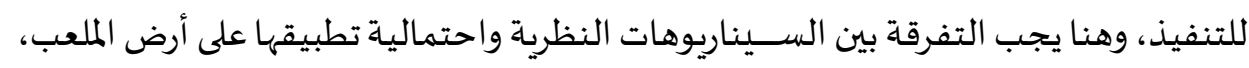

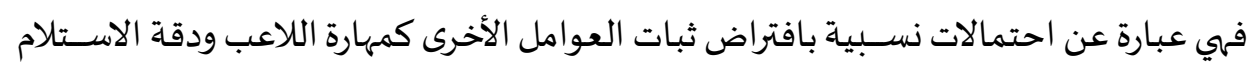

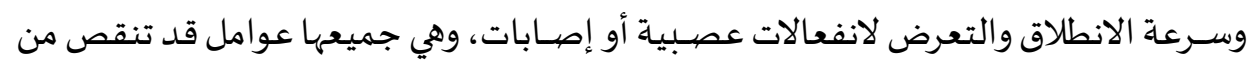
معدل الاحتمال. (خليفة، 2020)

فإذا كانت فرق كرة القدم قد اسـتغلت تحليل مجموعات البيانات الضـخمة لتطوير

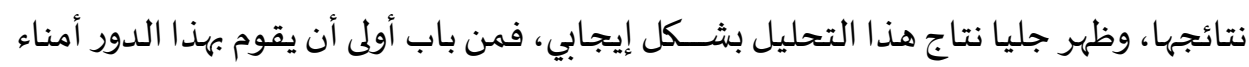

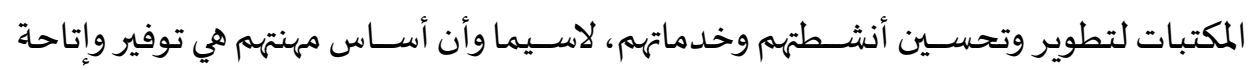
البيانات والمعلومات.

التحديات التي تواجه المكتبات للاستفادة من البيانات الضخمة :

ناقشـت العديد من الدراسـات قضـية ما تواجها المكتبات عند محاولاتها الاسـتفادة

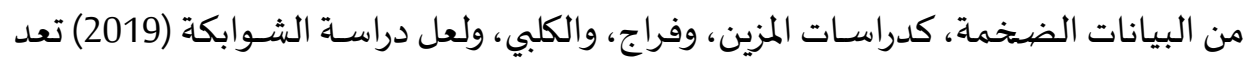
أفضل ما وقف عليه الباحث في تفصيل هذه التحديات، وإجمالا يمكننا أن نخلص باتل بالآي: أولا: تحديات متعلقة بالبيانات:

أ. الحجم (Volume) فمع نمو البيـانـات دون توقف، ومع ظهور مصــادر جـديـدة لإنتـاج

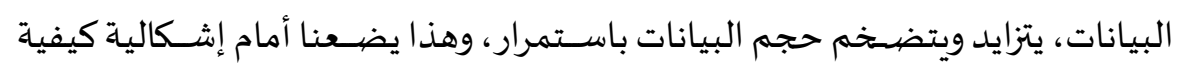

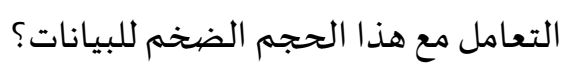

ب. الســرعة (Velocity) والتي تضــــنا أمام إشــكالية كيفية ملاحقة فيضـانـانات البيانات الناتجة وكذا مواجهة المتطلبات الآنية للمستفيدين في الوقت المطام 
ج. التنوع (Variety) وبين بيانات نصية وأخرى مرئية وثالثة مسـموعاة، وبين بيانات رقمية

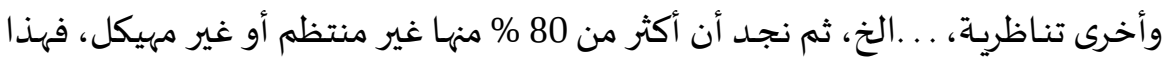

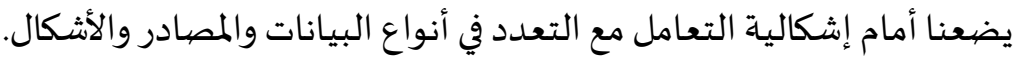

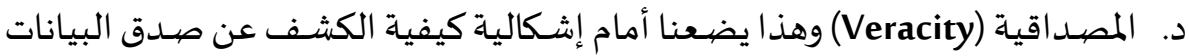

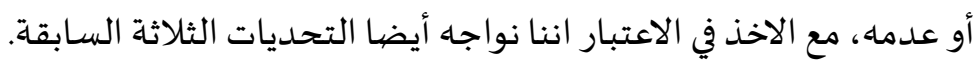

ثم نواجـه تحسدي الجودة (Quality) مـا مسـى جودة البيـانـات وملائمتهـا لطلبـات الباحثين؟، والتوافر (Availability) وما مدى شـــمولية تغطية البيانات؟ واكتشــاف البيانات

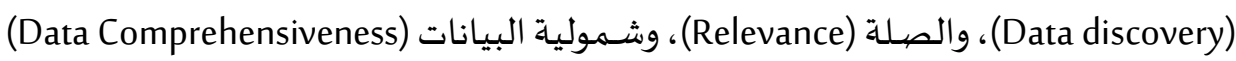
فهل هناك مناطق بدون تغطية؟ واكتشــاف البيانات: Data discovery فكيف يمكننا العثور

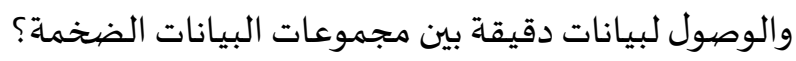

ثانيا: تحديات المعالجاة: Process challenges وتشمل:

أسـر البيانات، والمفاضلة بين البيانات من مصـادر مختلفة وتحويل البيانات إلى شكل

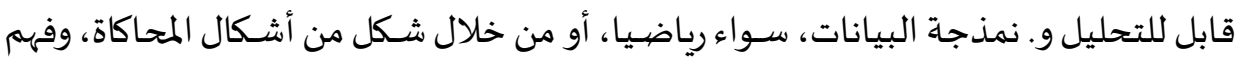
المخرجات، تصور وتقاسم النتائج.

ثالثا: التحديات الإدارية: Management challenges وتشمل: خصوصية البيانات، وأمن البيانات، وحوكمة البيانات وأخلاقيات البيانات وفضيلا عن هذا التفصيل يمكننا مناقشـة التحديات التي تواجه المكتبي في عصر البيانات الضخمة من الزوايا التالية (فراج، 2018) و(الشوابكة، منيل، 2019):

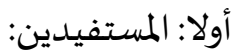
أ. توقعات المستفيد

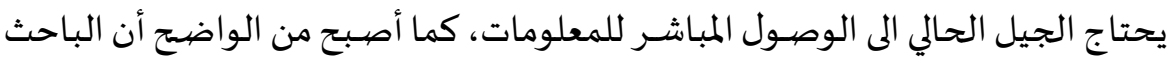

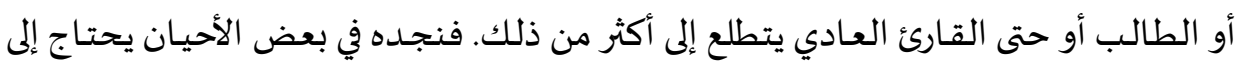

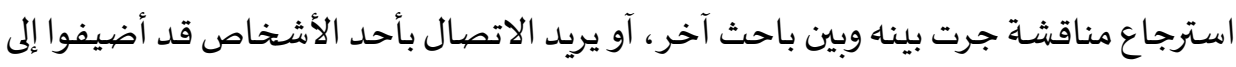

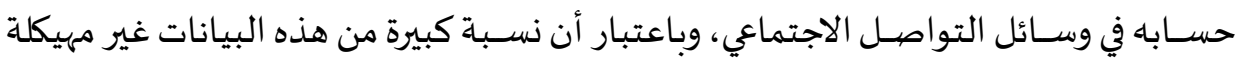


ولا منظمة من جهاة. وتزايدها من جهاة أخرى، أضسى من الصعب على قواعد البيانات في شكلها

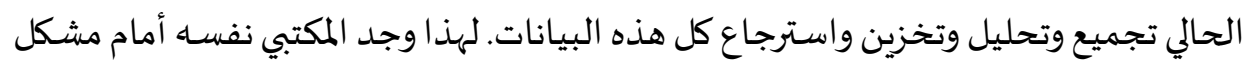
يستلزم إعادة النظر في كل التنظيم الداخلي للمكتبة (كباب، 2018). ب. احتياجات ومهارات الجيل الحالي للمستخدمين

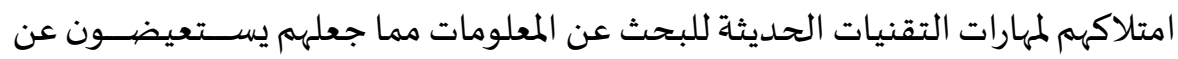

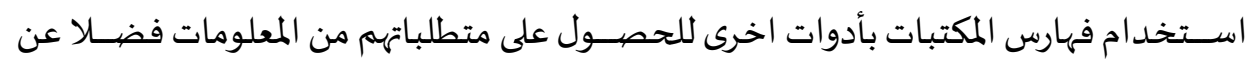

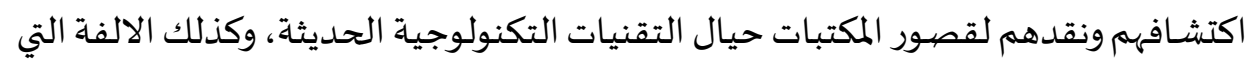

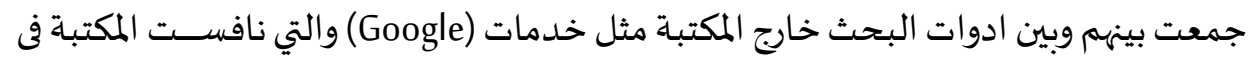

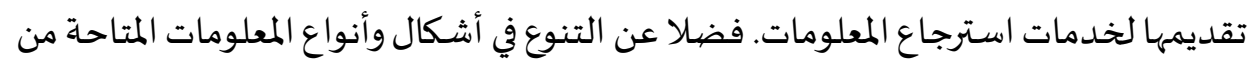
حولهم (نصـوص / صــور / مقاطع فيديو / ملفات صـوتية / خليط مما سـبق) مع الحاجة اليها.

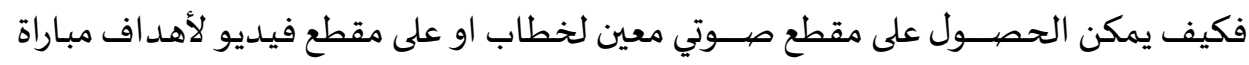

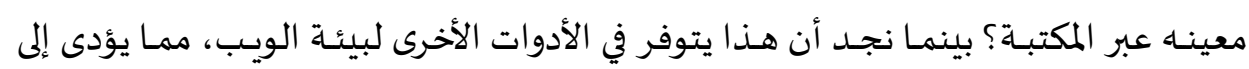

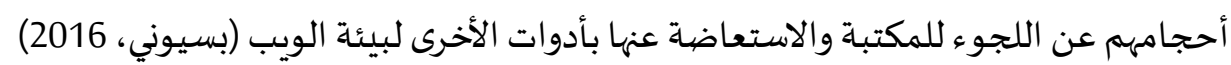

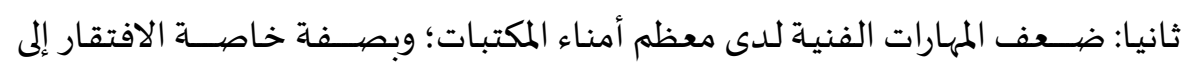

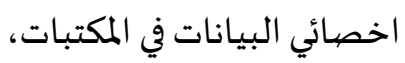

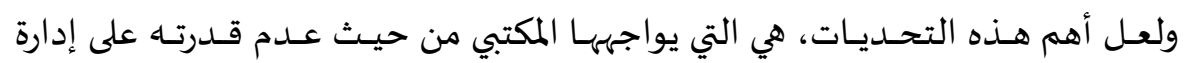

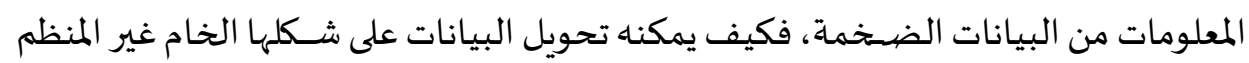

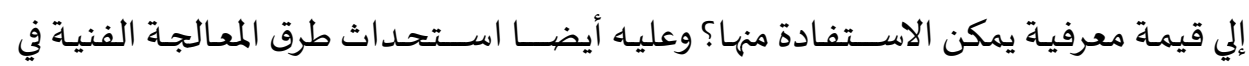

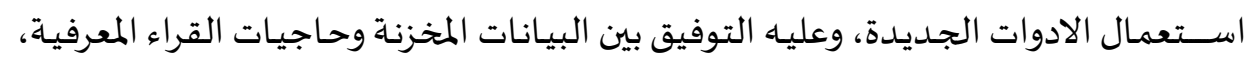

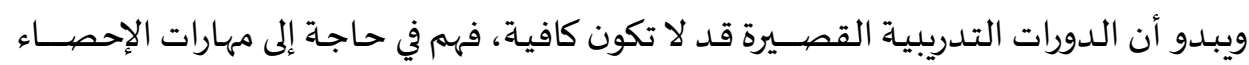

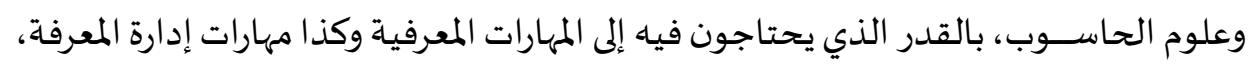

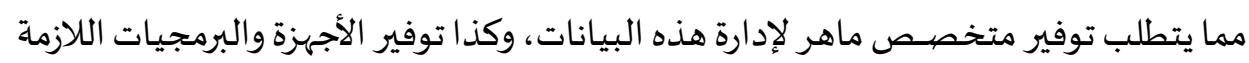

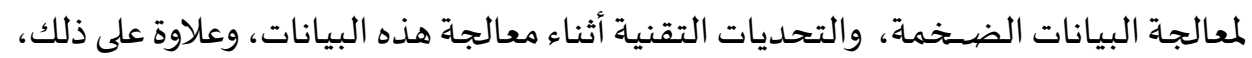

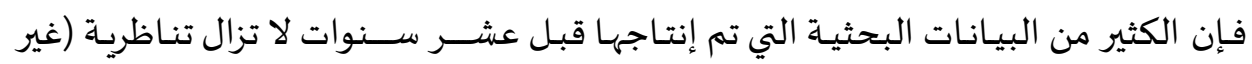

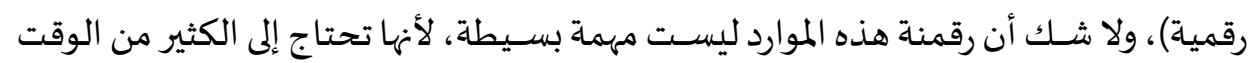


والموارد والموظفين. وكل ذلـك يتطلـب ميزانيـات قلمـا تتوافر في المكتبـات في ظل الظروف

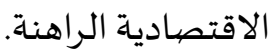

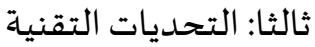

تقنيات مثل التقاط البيانات وتخزينها ومعالجتها وعرضـهـا، وتتوافر البيانات الموجودة في

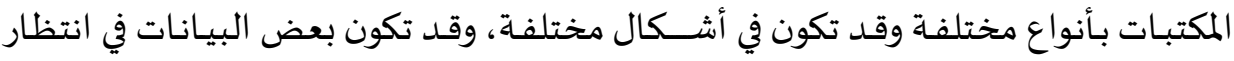

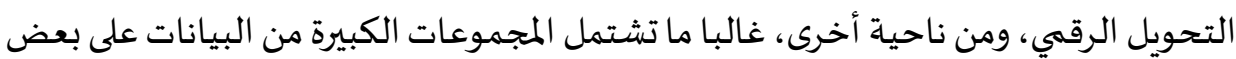

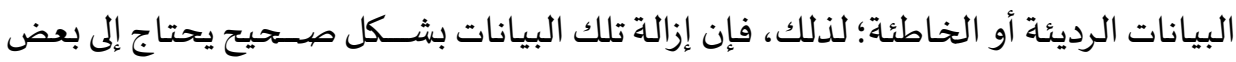

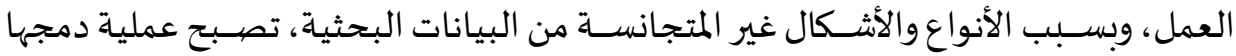

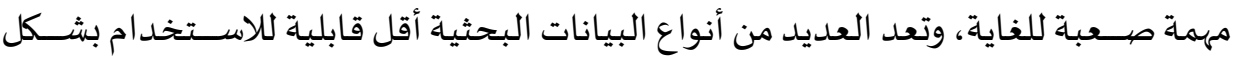

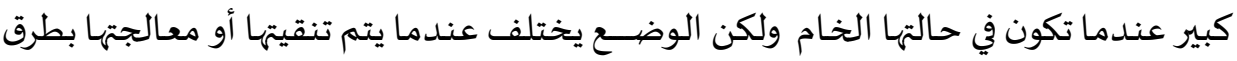

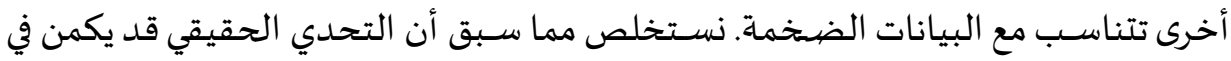

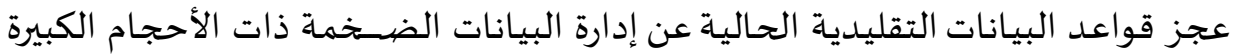
والأشكال والمصادر المتعددة (المزين، 2019) رابعا: قضايا الخصوصية وسرية وأمن البيانات قد تنشـأ مخاطر جديدة ناجمة عن حدوث اختراقات للنظام بسـبب إمكانية الوصــول إلى

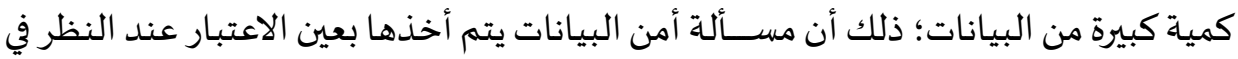

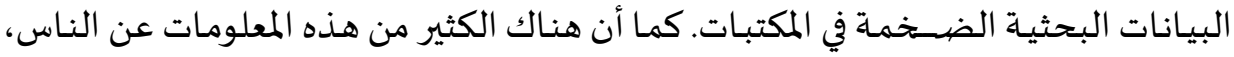

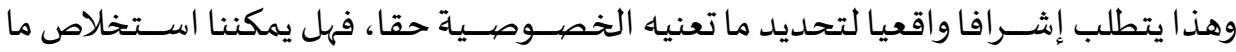
يكفي من المعلومات لمساعدة الباحثين دون المساس بخصيوصياة الأخرين؟ وأخيرا لابد أن ننوه إلى أن إدارة البيانات الضـخمة قد لا تتوافر لجميع المكتبات، فيمكننا

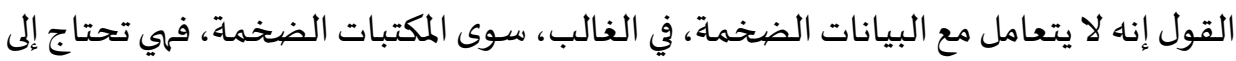

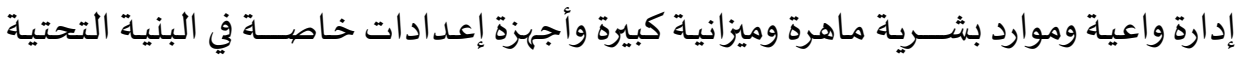

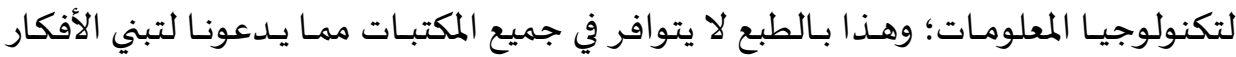

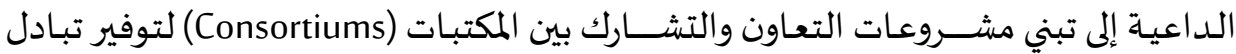

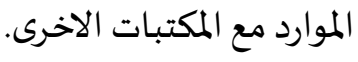




\section{دور المكتبيين في التعامل مع البيانات الضخمة:}

ونظرا لطبيعة عمل المكتبيين (أكادميين ومهنيين) والتي تدور في فلك المعلومات منذ نشـأتها

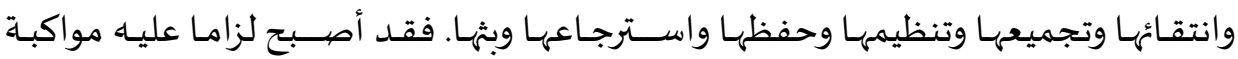

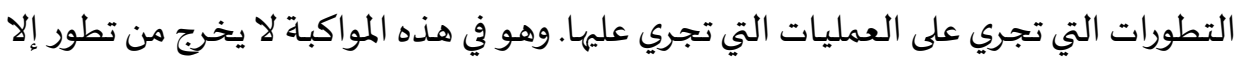

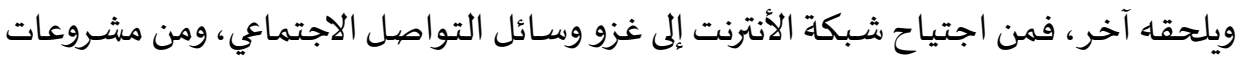

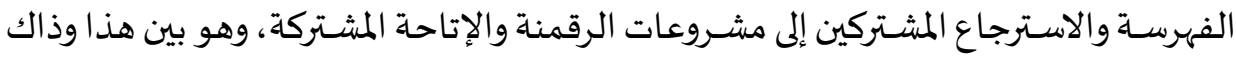
ينظر إلى سمات جمهور المكتبة من المستخدمين والتي تتصف بالآتي (محمود، 2019) : 1. امتلاكهم لمهارات التعامل مع أدوات ومحركات البحث عن المعلومات على الويب.

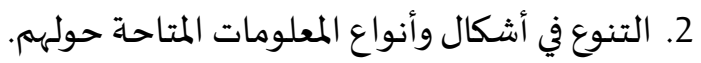

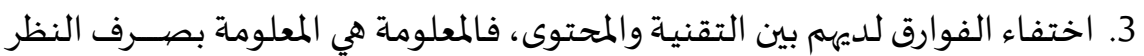
عن الشكل المقدمة فياء. 4. يتعاملون مع الويب -موفر المعلومات لهم - باعتباره جزء من المجتمع المحيط وليس كأحد التقنيات.

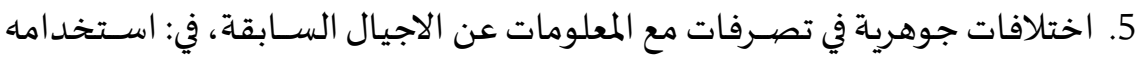
للمعلومات، تفاعله الشخصي، قيمها الاجتماعية 6. يتوقع امكانيـة الوصـــول للمعلومـة وقت ما يحتـاجها ومن اي مكان، ويتوقع تأقلم الخدمات مع احتياجاته الخاصية.

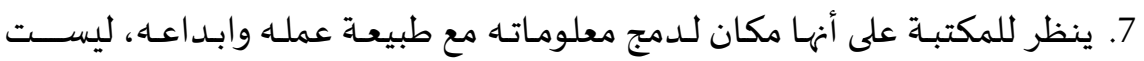
لاستعارة الكتب فقط 8. ظهور العديد من المواقع الالكترونية التي تتيح المعلومات ومصـــادرها بشـكل واســع امام المستخدم كمنافس مباشر للمكتبات

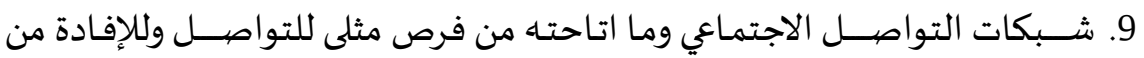

$$
\text { المعلومات ومصيادرها وتبادلها. }
$$
10. أكبر شريحة في المجتمع العربي وتتزايد مع مرور الزمن. 
وعليـه فلا بـد على المكتبيين أن تتغير رؤيتهم من أن اجتيـاز الـدراســــة الجـامعيـة أو حتى

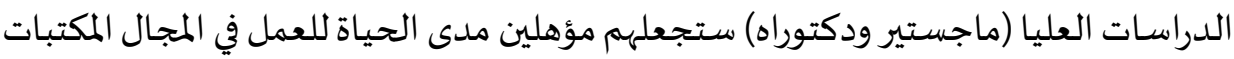

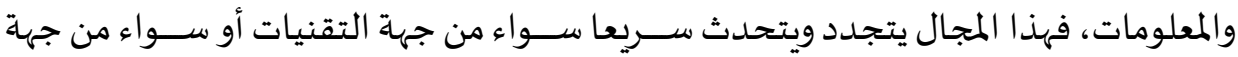

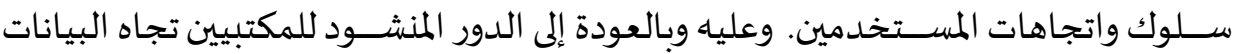
الضخمة باعتبارها أحد التحديات الحديثة، فيجب على المكتبيين القيام بالدور الاتي: ولئ 1. إنشـــاء وعقد النـدوات والبرامج للتوعية ولنشــــر القنـاعـات بأهميـة قيمـة البيانات الضشمة Data literacy بين أوسـاط المكتبيين مع التركيز على توصيل هذه المفاهيم لمدراء المكتبات 2. وضـع البرامج التدريبية المناسبة لتدريب المكتبيين على التعامل مع البيانات الضشخمة

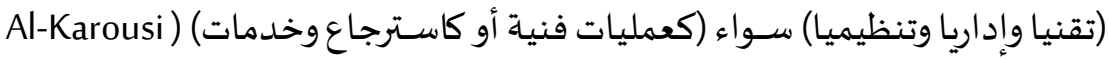
(2018 \& Al-Barashdi 3. اعداد المناهج والمقررات الدراسـية الداعمة للاسـتفادة من البيانات الضشخمة، سـواء بوضيع مقررات دراسية خاصية مستقلة عنها، أو ضـمن مقررات دراسية أخرى تتناول

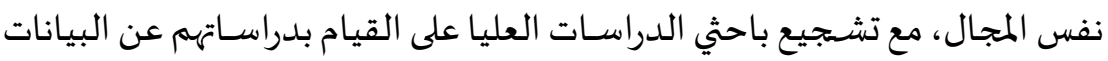

$$
\text { الضخمة والموضوعات المتعلقة بها. }
$$

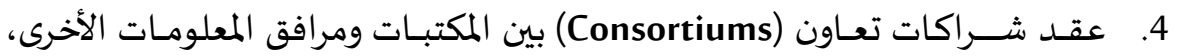

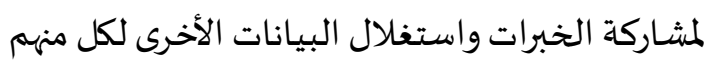

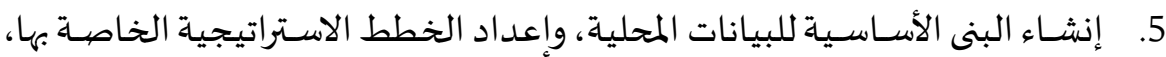
وإنشاء أرشيفات البيانات في أي من المجالات التخصصية (فراج، 2018)

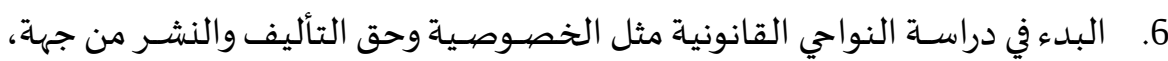

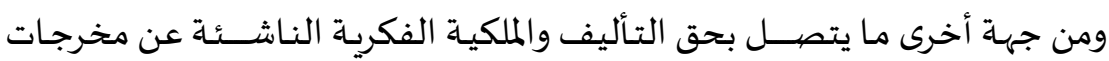

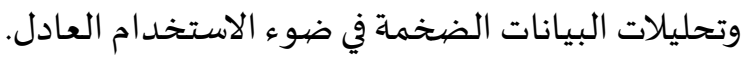


وتتفق الدراسات التي تم تناولها الباحث مع هذه الدراسـة في عدة أمور من أهمها:

$$
\text { أولا: البيانات الضخمة }
$$

O تمتلك الكثير من المكتبـات مجموعات من البيـانات الضــخمـة، والغـالبيـة منهـا غير مستغل.

O المكتبات الضخمة هي من تستطيع إدارة وتحليل مجموعات البيانات الضخمة.

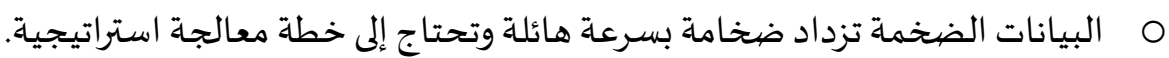

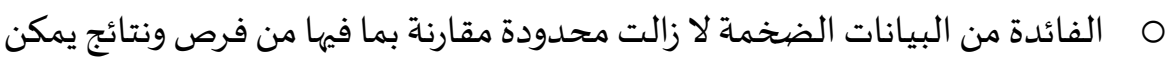

$$
\text { الحصول عليها بعد التحليل. }
$$

تساعد البيانات الضخمة متخذي القرار في تعرف احتياجات المجتمع تمهيد الاتخاذ

$$
\text { القرار السليم بتلبيته (المزين، 2019) }
$$

تسهم البيانات الضخمة في تطوير وتحسين واستحداث خدمات المعلومات المبندات إذا ما تم

$$
\text { معالجتها وإدارتها بشكل جيد (المزين، 2019) }
$$

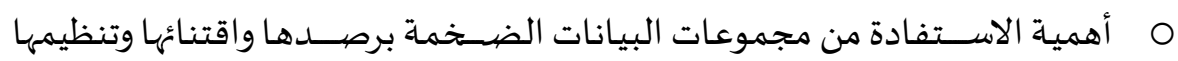

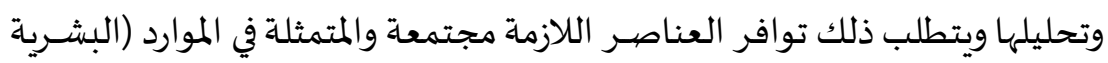

$$
\text { والمادية والتقنية (الكلبي، 2018) }
$$

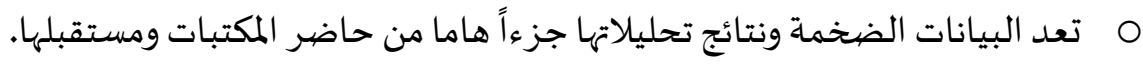

$$
\text { ثانيا: الموارد البشرية }
$$

O تعاني المكتبات العربية نقصــا في الموارد البشـرية المؤهلة والمتخصــصــة في إدارة

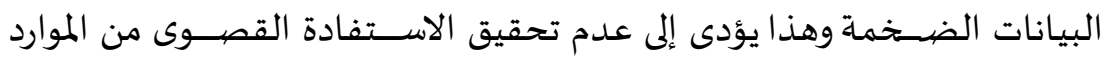
التقنية والمادية المتوافرة بالمكتباة.

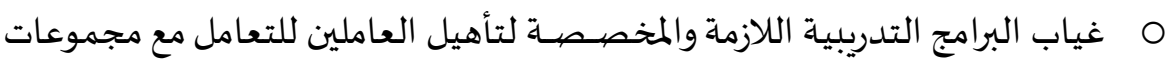

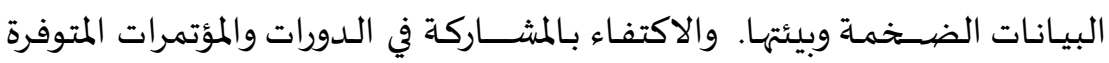

$$
\text { (المزين، 2019) }
$$


O غياب التشريعات القانونية التي تقنن العملية ككل (المزين، 2019) O خصوصية البيانات الخاضعة للتحليل وقضايا الملكية الفكرية للبيانات هو مثار جدل كبير حاليا، والأنظار تتجها نحو ممارسات كبريات الشركات المعنية بالبيانات لهات

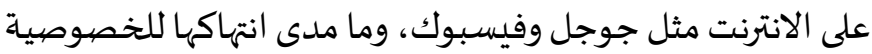
رابعا: التقنيات

تعد تقنيات الحوسبـة السسحابية من أهم الحلول لإيجاد مسـاحات تخزينية للبيانات

الضخممة، وتساعد في التعامل معها بالسرعة المناسبة (الكلبي، 2018)

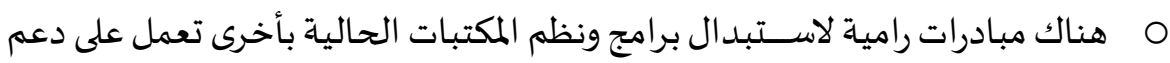

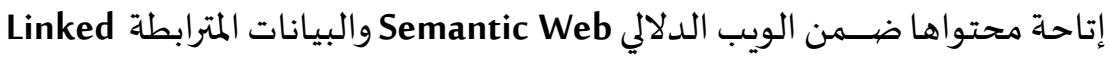

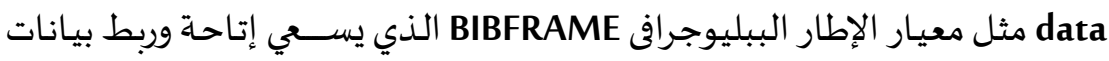

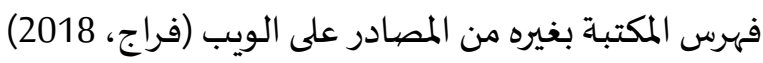

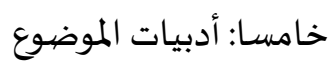

o الانتـاج الفكري المنشــور عربيا - أو حتى عالميا - حول البيانات الضـخمة في المكتبات لازال يركز على الجوانب النظرية (الشوابكة، 2018)

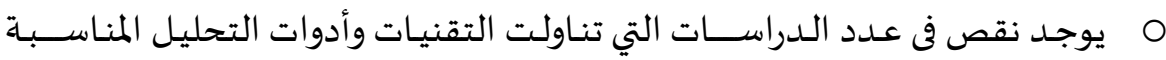

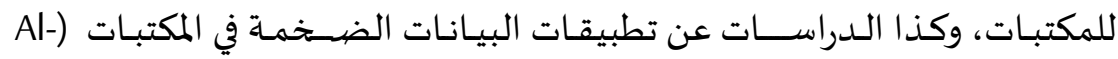
(2018 Karousi \& Al-Barashdi O لم يقف الباحث على دراسـات تتناول موضهوع الخصيوصية وحقوق التأليف من جهة وعن الاستخدام العادل للمعلومات من جهة أخرى.

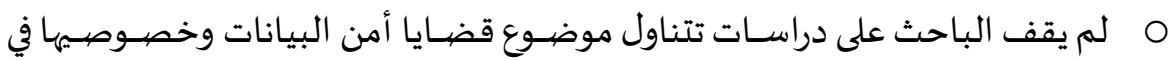
المكتبات. 


\section{توصيات الدراسة:}

من خلال العرض السابق، يقترح الباحث توصيات عشر نسردها فيما يلي:

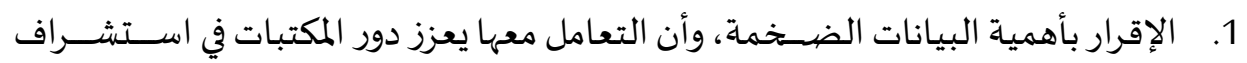
مستقبل أفضل.

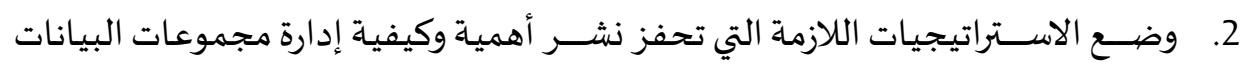
الضخمة.

3. ضــرورة التخطيط من قبـل القـائمين على أقســـام المكتبـات والمعلومـات في الجـامعـات

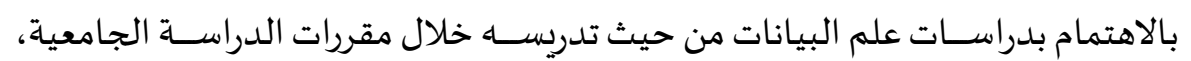

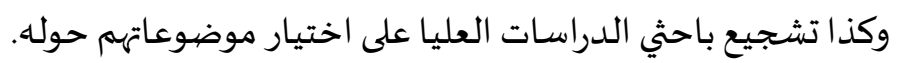

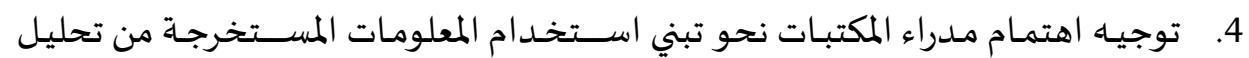
البيانات الضخمة في اتخاذ قراتهه.

5. تجهيز البرامج التدريبية المتخصصة لتأهيل العاملين الحاليين لإدارة البيانات الضخمادمة.

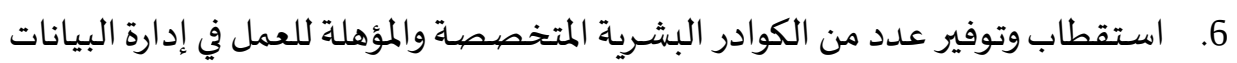
الضخمة.

7. مراجعـة إمكانيـات البنى التحتيـة والتشـــيليـة وايفـاء متطلبـات التعـامل مع البيـانـات الضخمة. 8. توجيـه اهتمام القـائمين على عمليـات البيـانـات الضــخمـة بتخزينها على مســـودعـات الحوسبة السحابية. 9. سـن التشـريعات القانونية التي تحمي الملكية الفكرية والخصــوصيـية وحقوق التأليف من جهة، وتوازن ذلك، وتسمح بالاستخدام العادل للمعلومات من جهات أخرى.

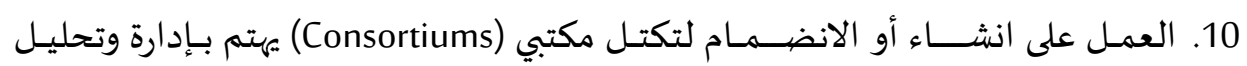
مجموعات البيانات الضخمة.

\section{الخاتمة}

علي أي حال، فإن البيانات الضخمة بمفردها لن تؤدي بالضرورة لرسم سياسـات أفضل

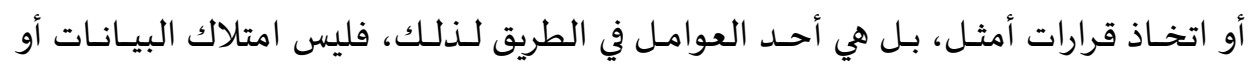


الاكتفاء بتحليلها هو الهدف النهائي، ولكن كيفية توظيف المعلومات المســتخرجة وتحويلها إلى

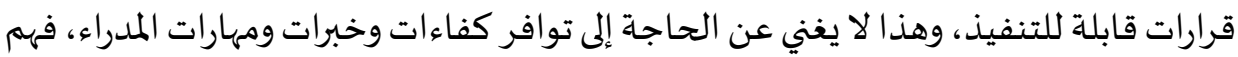

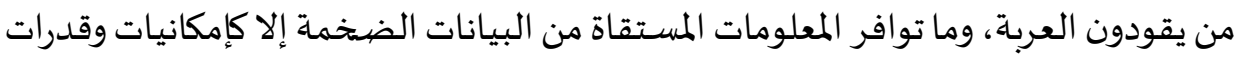

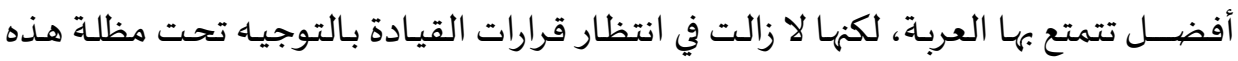

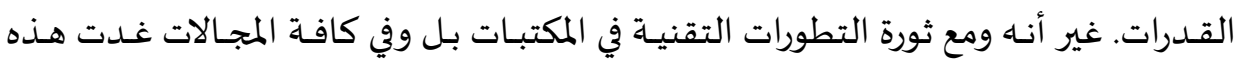

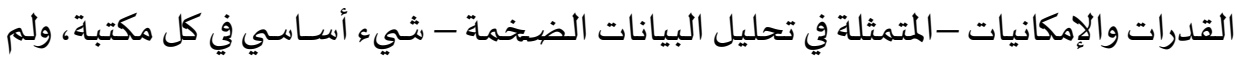

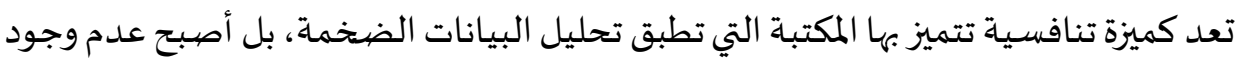

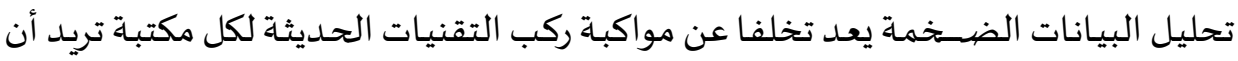

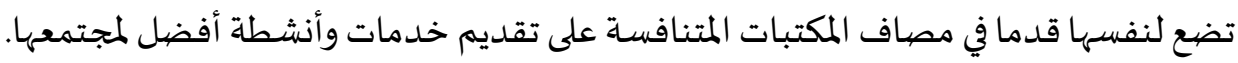




\section{المراجع}

\section{أولا باللغة العربية:}

1. 20 حقيقة مذهلة عن ثورة البيانات الضخمة - Egyptian Journal of Information Compunet Date: June 1, 2016

2. البار، عدنان مصطفى. (2018) البيانات الضخمة ومجالات تطبيقها. - تم الاسترجاع 3

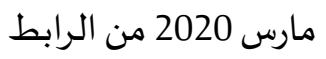

https://www.kau.edu.sa/GetFile.aspx?id=285260\&fn=Article-of-the-WeekAdnan-Albar-01-November-2017.pdf

3. بسيوني، أحمد سعد الدين (2016) بيئة الفهارس في المكتبات: بين الواقع والطموح -.

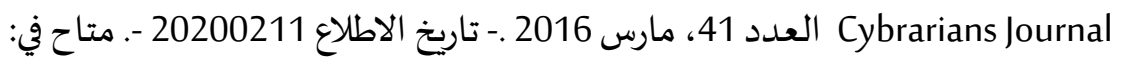
http://journal.cybrarians.info/index.php?option=com_content\&view=article\&i $\underline{\mathrm{d}=722: \text { abassiouni\&catid=286: } \text { conf\&Itemid=104 }}$

4. بوعناقة، سعاد (2018) .البيانات الضخمة في قطاع المكتبات :نقاط القوة والضعف

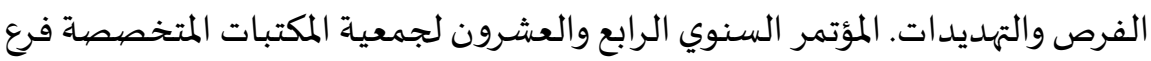

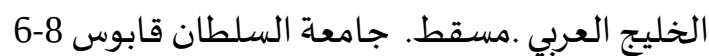

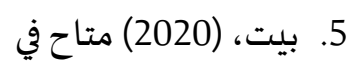

https://specialties.bayt.com/ar/specialties/q/132885/\%D9\%85\%D8\%A7

\%D9\%87\%D9\%8A-\%D9\%88\%D8\%AD\%D8\%AF\%D8\%A7\%D8\%AA\%D9\%82\%D9\%8A\%D8\%A7\%D8\%B3\%D9\%85\%D8\%B3\%D8\%AD\%D8\%A7\%D8\%AA-

\%D8\%A7\%D9\%84\%D8\%AA\%D8\%AE\%D8\%B2\%D9\%8A\%D9\%86\%D9\%88\%D8\%B9\%D9\%84\%D8\%A7\%D9\%82\%D8\%AA\%D9\%87\%D8\%A7 /-\%D8\%A8\%D8\%A8\%D8\%B9\%D8\%B6\%D9\%87\%D8\%A7

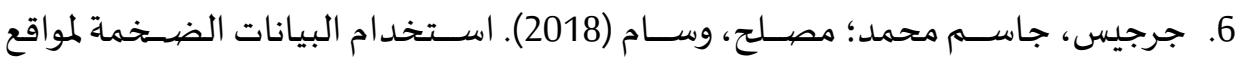

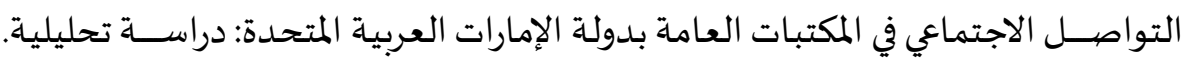


المؤتمر الســـوي الرابع والعشــرون لجمعية المكتبات المتخصــصــة فرع الخليج العربي . مسقط :جامعة السلطان قابوس 8-6 مارس 2020

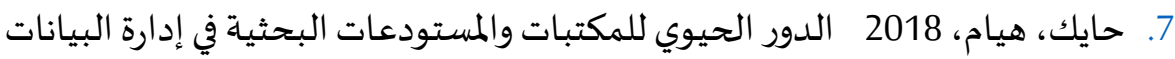

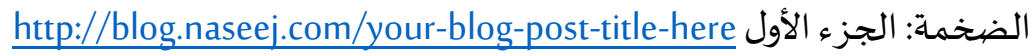
8. حبش، محمد. لمحاة عن البيانات الضخمة" /https://www.tech-wd.com/wd/2013/07/24/what-is-big-data : 2020 9. خليفة، ايهاب. (2020) كيف غيّر "علم البيانات الضخمة" أداء "فريق ليفربول"؟ تم https://futureuae.com/ar- الاسترجاع في 16 فبراير 2020 AE/Mainpage/Item/5216/data-science-\%D9\%83\%D9\%8A\%D9\%81\%D8\%BA\%D9\%8A\%D9\%91\%D8\%B1-\%D8\%B9\%D9\%84\%D9\%85\%D8\%A7\%D9\%84\%D8\%A8\%D9\%8A\%D8\%A7\%D9\%86\%D8\%A7\%D8\%AA\%D8\%A7\%D9\%84\%D8\%B6\%D8\%AE\%D9\%85\%D8\%A9\%D8\%A3\%D8\%AF\%D8\%A7\%D8\%A1-\%D9\%81\%D8\%B1\%D9\%8A\%D9\%82\%D9\%84\%D9\%8A\%D9\%81\%D8\%B1\%D8\%A8\%D9\%88\%D9\%84 10.الزلباني، محمد مسـعد (2019) المتطلبات التقنية لمؤسـســات المعلومات لمواكبة مجتمع

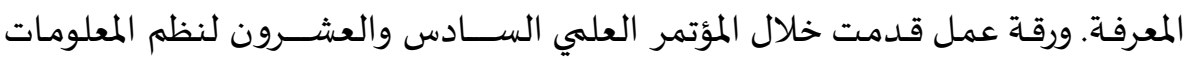
وتكنولوجيا الحاسـبات - ثورة البيانات لتعزيز التخطيط القومي والتنمية المســـدامة 2019

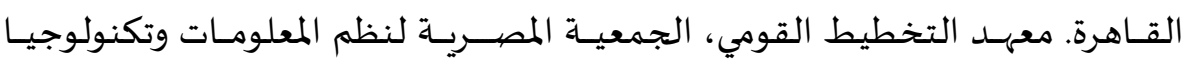
الحاسبات. 11.الســالمى، جمال وعرابة، ســيد (2018). البيانات الضــخمة ودورها في دعم اتخاذ القرار

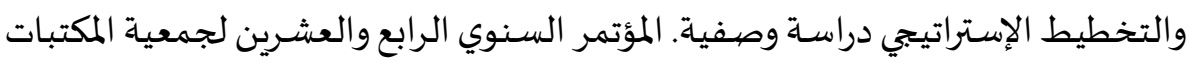

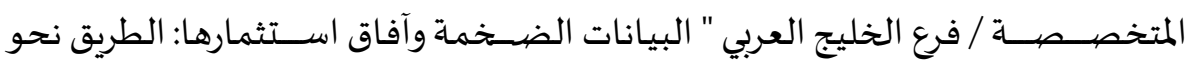

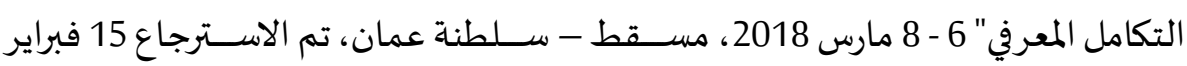
2020 من الرابط - https://www.researchgate.net/publication/334194323 
12. الشامي، أحمد محمد. موسوعة مصطلحات المكتبات والمعلومات والأرشيف = Library Archival Terminology Information and http://www.elshami.com:^j

13.الشـوابكة، يونس أحمد إسـماعيل (2018) ـ الوعى بمفهوم البيانات الضشخمة (Big Data)

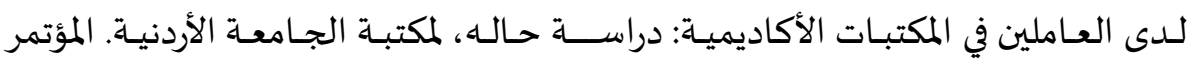

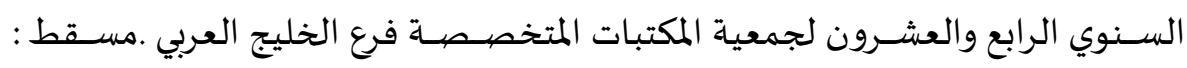
جامعة السلطان قابوس. 14.الشـــوابكة، يونس أحمد (2019) البيانات الضـخـمة في المكتبات: تســاؤلات حول المفهوم،

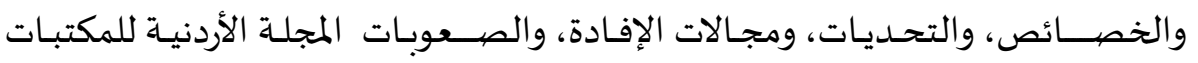

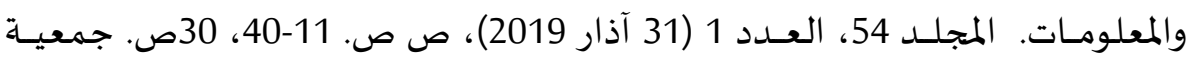
المكتبات والمعلومات الأردنية

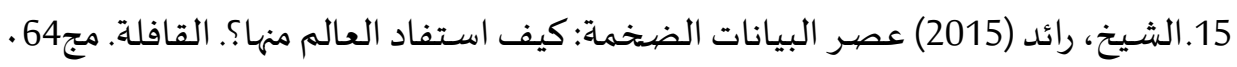

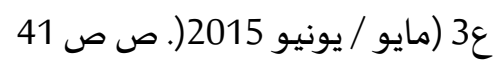

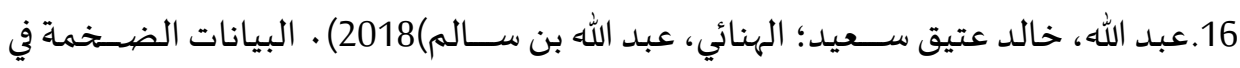
مكتبات جامعة السـلطان قابوس: واقعها ومســوى الاســفـادة منها ن وجهانة نظر موظفيها.

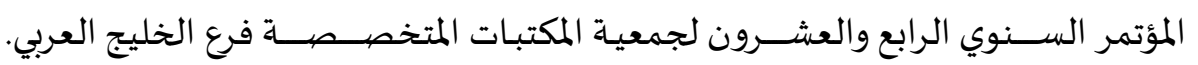
مسقط: جامعة السلطان قابوس). 17.العميري، منال حمد ان سعيد (2018) . البيانات الضخمة في المكتبات الأكاديمية في سلطنة عمان: الواقع والتحديات. المؤتمر السـنوي الرابع والعشـرون لجمعية المكتبات المبات المتخصصية

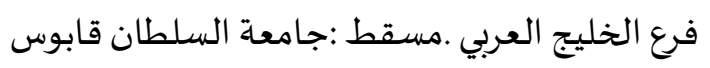

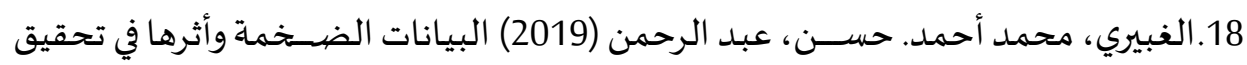

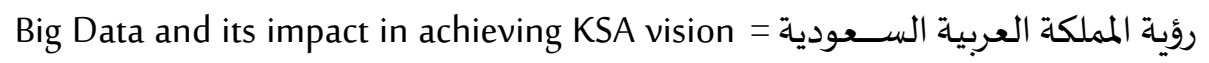
2030. - Applied study .Strategy \& Development Review. Aug2019 Part 1, Issue 17bis, p32-51. 20p. .51 Language: Arabic. , Database: Arab World Research Source 
19.فراج، عبد الرحمن (2018) البيانات الضـخمة في تخصــص المكتبات والمعلومات. أحوال

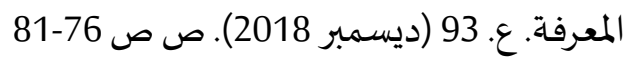

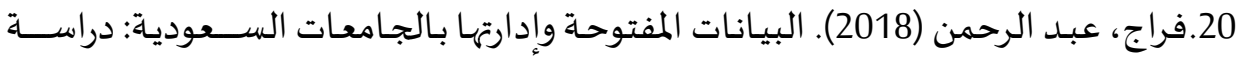

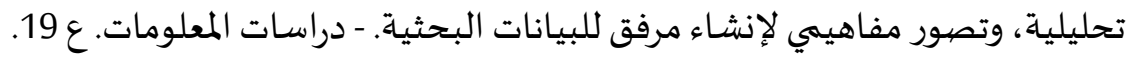

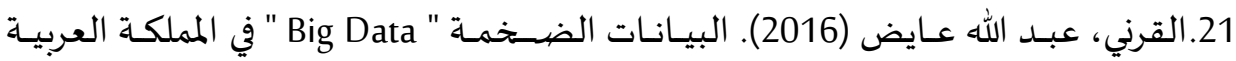

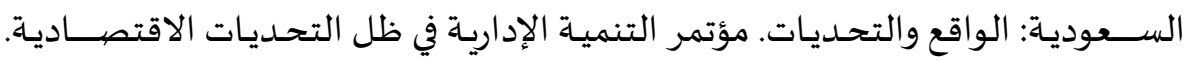

$$
\text { الرياض: معهد الإدارة العامة، (22-24 نوفمبر) }
$$

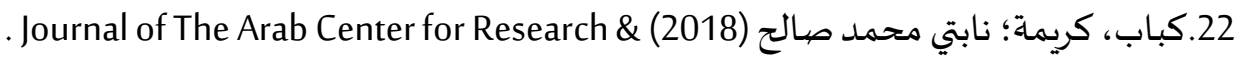
Studies in Library \& Information Sciences. Jun2018, Vol. 5 Issue 10, p196-210.

15p. Language: Arabic. , Database: Arab World Research Source 23.الكلبي، علي بن ذيب (2018). أهمية تحليل البيانات الضـخممة في اتخاذ القرار في جامعـة

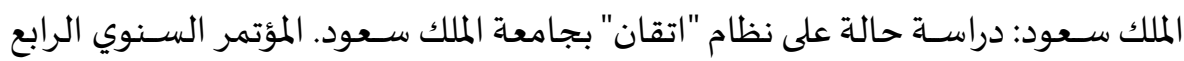

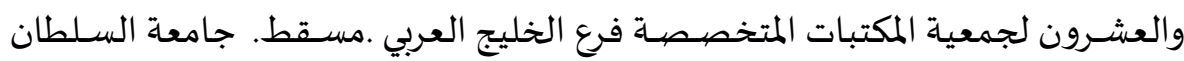

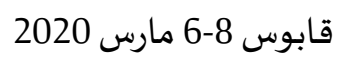

24.لستر، جون، ووالاس سي كويلر الابن. (2012). أسس دراسات المعلومات؛ الإلمام بالمعلومات

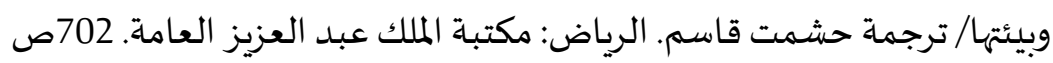
25.مرسال، محيي الدين كوكو بخيت (2018). دور وأهمية المكتبات الجامعية في إدارة البيانات

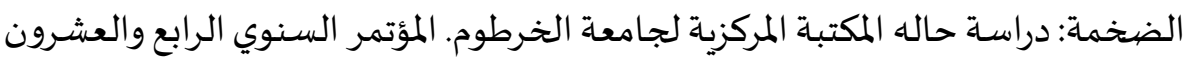

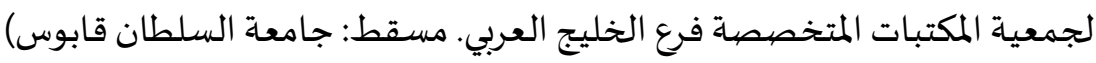

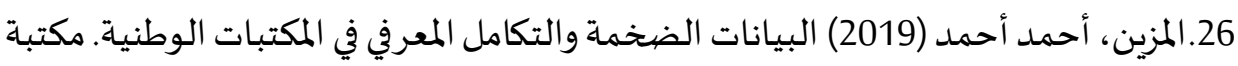
الكويت الوطنية أنموذجا. المجلة العلمية للمكتبات والوثائق والمعلومات متاح على الرابط المبات https://jslmf.journals.ekb.eg/article_36208_39cce969a2d2f2156f9129bbd02d

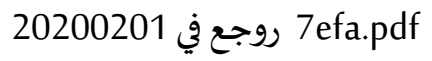
27.الهادي، محممد محمـد (2019) ثورة البيـانـات المعـاصيـرة: الواقع والتحـديـات. ورقـة عمل

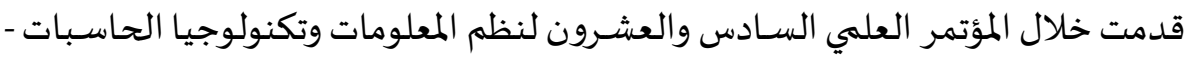
ثورة البيانات لتعزيز التخطيط القومي والتنمية المستدامة 2019 القاهرة. معهد التخطيط 


$$
\text { القومي، الجمعية المصرية لنظم المعلومات وتكنولوجيا الحاسبات. }
$$

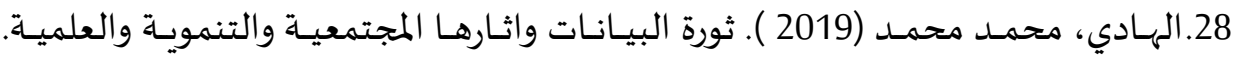

القاهرة: روابط للنشر وتقنية المعلومات ص. 107

29. هلالي، امانى محمد، محمد حسـن (2016) آثر ثورة البيانات على البيئة المعلوماتية لمتخذي إندي

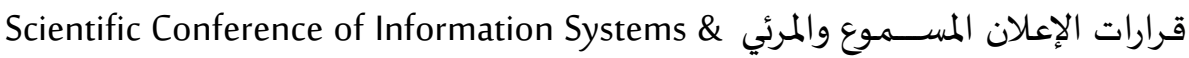

Computer Technology Date: January 1, 2016

30.هكذا يستغل ليفربول "البيانات الضخمة" للفوز بالدوري الإنجليزي (2020) تم الاسترجاع

1 فttps://www.hespress.com/sport/458040.htm| فبراير 2020 من الرابط فيطونيان

31.وانج، لين (2019) توأمة علم البيانات مع علم المعلومات بمدارس علم المكتبات والمعلومات

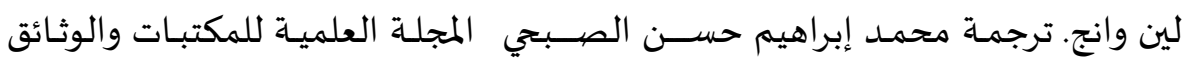

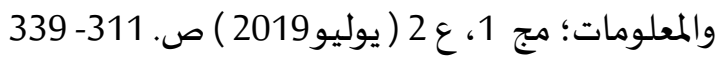

\section{ثانيا المراجع باللغة الانجليزية}

32. Bieraugel. Mark (2016). Keeping Up With Big Data. Association of College \& Research Libraries (ACRL). Retrieved 11 December, 2019 from: http://www.ala.org/acil/publications/keeping up with/big data

33. Hassaneen. Badria Mohamed. (2019) Internet of Things and Big Data:

Revolution in Education. (Retrieved 22 January, 2019) from

http://www.naturalspublishing.com/files/published/701538jy1g89sq.pdf

34.Jharotia, Anil Kumar (2018) Big Data Technology: Big Opportunity for

Librarians - Anil Kumar Jharotia Librarian Tecnia Institute of Advanced

Studies, GGSIP University, Delhi, India. (Retrieved 11 December, 2019) from

https://www.researchgate.net/publication/326972552_Big_Data_Technology

Big_Opportunity_for_Librarians 
35.Al-Karousi, Rahma\& Al-Barashdi, Hafidha(2018) . Big Data in academic libraries: Literature review and future direction. 24th Annual Conference of the SLA/AGC Muscat: Sultan Qaboos University (6-8 March) 2018,

36. Manaseer, Saher and others (2018). Big Data Investment and knowledge Integration using HADOOP Frame work in Academic Libraries. 24th Annual Conference of the SLA/AGC.Muscat: Sultan Qaboos University (6-8 March) 2018

37.Mavodza, Judith 2018). The association between academic research information and Big Data. 24th Annual Conference of the SLA/AGC. Muscat: Sultan Qaboos University (6-8 March) 2018.

38.Al-Mesad, Aseel (2018) The Preparation of Big Data Phenomena in the Public Sector in Kuwait. 24th Annual Conference of the SLA/AGC. Muscat: Sultan Qaboos University (6-8 March) 2018

39. Osman, Rania Ramadan (2018) The Evolution of Data. From Data to Big Data. Are we ready for the big data technology in the library community. 24th Annual Conference of the SLA/AGC.Muscat: Sultan Qaboos University (6-8 March) 2018

40.Zicari, R. (2017). Big Data: Challenges and Opportunities. (Retrieved 11 December, 2019) from:

http://odbms.org/wp-content/uploads/2013/07/Big-Data.Zicari.pdf 